\title{
Identification of Bacterial Blight Resistance Loci in Rice (Oryza sativa L.) against Diverse Xoo Thai Strains by Genome-Wide Association Study
}

\author{
Siriporn Korinsak ${ }^{1}$, Clive T. Darwell ${ }^{1}$, Samart Wanchana ${ }^{1}\left(\right.$, Lawan Praphaisal ${ }^{1}$, Siripar Korinsak ${ }^{1}{ }^{\circledR}$, \\ Burin Thunnom ${ }^{1}$, Sujin Patarapuwadol ${ }^{2}(D)$ and Theerayut Toojinda ${ }^{1, *}$ \\ 1 National Center for Genetic Engineering and Biotechnology (BIOTEC), 113 Thailand Science Park, \\ Pahonyothin Road, Khlong Nueng, Khlong Luang, Pathum Thani 12120, Thailand; \\ siripornkorinsak@gmail.com (S.K.); cliveterence.dar@biotec.or.th (C.T.D.); samart.wan@biotec.or.th (S.W.); \\ yingyuy18@gmail.com (L.P.); siripar.skk@gmail.com (S.K.); burinthnm@gmail.com (B.T.) \\ 2 Department of Plant Pathology, Faculty of Agriculture at Kamphaeng Saen, Kasetsart University, \\ Kamphaeng Saen Campus, Nakhon Pathom 73140, Thailand; agrsujp@ku.ac.th \\ * Correspondence: theerayut@biotec.or.th
}

Citation: Korinsak, S.; Darwell, C.T.; Wanchana, S.; Praphaisal, L.;

Korinsak, S.; Thunnom, B.;

Patarapuwadol, S.; Toojinda, T. Identification of Bacterial Blight Resistance Loci in Rice (Oryza sativa L.) against Diverse Xoo Thai Strains by Genome-Wide Association Study. Plants 2021, 10, 518. https:// doi.org/10.3390/plants10030518

Received: 2 February 2021

Accepted: 5 March 2021

Published: 10 March 2021

Publisher's Note: MDPI stays neutral with regard to jurisdictional claims in published maps and institutional affiliations.

Copyright: (c) 2021 by the authors. Licensee MDPI, Basel, Switzerland. This article is an open access article distributed under the terms and conditions of the Creative Commons Attribution (CC BY) license (https:/ / creativecommons.org/licenses/by/ $4.0 /)$.

\begin{abstract}
Bacterial leaf blight (BLB) is a serious disease affecting global rice agriculture caused by Xanthomonas oryzae pv. oryzae (Xoo). Most resistant rice lines are dependent on single genes that are vulnerable to resistance breakdown caused by pathogen mutation. Here we describe a genome-wide association study of 222 predominantly Thai rice accessions assayed by phenotypic screening against 20 Xoo isolates. Loci corresponding to BLB resistance were detected using $>142,000$ SNPs. We identified 147 genes according to employed significance thresholds across chromosomes 1-6, 8, 9 and 11. Moreover, 127 of identified genes are located on chromosomal regions outside estimated Linkage Disequilibrium influences of known resistance genes, potentially indicating novel BLB resistance markers. However, significantly associated SNPs only occurred across a maximum of six Xoo isolates indicating that the development of broad-spectrum Xoo strain varieties may prove challenging. Analyses indicated a range of gene functions likely underpinning BLB resistance. In accordance with previous studies of accession panels focusing on indica varieties, our germplasm displays large numbers of SNPs associated with resistance. Despite encouraging data suggesting that many loci contribute to resistance, our findings corroborate previous inferences that multi-strain resistant varieties may not be easily realised in breeding programs without resorting to multi-locus strategies.
\end{abstract}

Keywords: bacterial leaf blight; rice; GWAS; Xanthomonas oryzae pv. oryzae

\section{Introduction}

Bacterial leaf blight (BLB), caused by Xanthomonas oryzae pv. oryzae (Xoo), is a serious crop disease causing major losses to rice production around the world [1]. BLB has been estimated to cause $20-80 \%$ of rice yield loss [2-5]. In recent decades, increases in BLB outbreaks have been recorded and often attributed to global temperature rises linked to ongoing anthropogenic climate change [6-8]. Additionally, increases in genetic diversity of $\mathrm{Xoo}$, and emergence of new races are regularly reported in intensive rice production areas where susceptible rice varieties are often used.

The use of diverse rice varieties [9], misapplication of chemicals [10] and natural mutations of the pathogen [11], have been suggested as the agronomic drivers exacerbating the emergence of novel Xoo races and assisting their host shifts across rice varieties and to new geographic localities. In Thailand, outbreaks have been regularly reported since 1957 [12-14] and high genetic diversity among Xoo isolates has been documented [12,13]. There are a growing number of reports on the genetic diversity of Xoo at both regional and national scales that likely result from practices of continuous mono-cropping, the deploy- 
ment of rice cultivars with a narrow genetic base, and the anthropogenically mediated crossing of geographical barriers through seed allocation and germplasm exchange $[9,12,15-19]$.

It is established that rice cultivars that rely on single major genes for resistance are more susceptible to suffer resistance breakdown by pathogen mutational dynamics than cultivars featuring multi-locus-based resistance phenotypes [20]. Thus, breeding programs that target the development of multi-locus resistance varieties should prove a more viable strategy to ensure long-term goals in sustainable rice production [21-24].

Numerous resistance $(R)$ genes for BLB have been discovered during the last 50 years. At least 43 resistance genes (labelled with $R$ prefixes) have been identified and characterized from various rice accessions including its wild relatives [25-36]. Of these, 16 genes reportedly function as recessive genes with the rest characterized as dominant [37]. Gene functionality is often shown to be influenced by genetic background and plant developmental stage, e.g., Xa1, Xa3, Xa21, xa25, Xa26 [38]. Currently, nine $R$ genes (Xa1, Xa3/Xa26, $x a 5, X a 10, x a 13, X a 23, x a 25, X a 27, X a 21)$ have been cloned [35,39-46], and are thus associated with defined chromosomal locations relative to rice reference genomes. The cloned $R$ genes encode various types of protein such as a cytoplasmic domain containing a serine-threonine kinase, a transmembrane domain, an extracellular domain with leucine rich repeat (LRR) receptor kinase like proteins, NB-LRR protein, the gamma subunit of transcription factor IIA (TFIIA $\gamma$ ), a plasma membrane protein of the MtN3/saliva family, and an unknown protein [38-40,42,43,45,47,48]. Although the identification of $R$ genes is increasing rapidly, the development of race/isolate specific or broad-spectrum resistance against Xoo remains elusive.

Recently, current advances in high-density molecular marker platforms and the application of genetic resources with assorted diversity panels has enabled the accurate identification of genomic locations and candidate genes for traits of interest through genome-wide association studies (GWAS) and allele mining. GWAS has been widely applied to identify genes of interest in a number of crop species, such as rice, maize, sugarcane, cotton, wheat, barley, potato and soybean [49-52]. GWAS methods permit the identification of novel alleles that are likely to be useful in crop improvement programs [53]. In rice, GWAS has been used to identify DNA markers associated with traits for grain quality, yield (and its correlates), stigma and spikelet characteristics, eating and cooking qualities, and diseases resistance such as for sheath blight, blast and BLB [24,25,54-59]. GWAS studies on BLB have identified loci associated with cloned and fine-mapped genes $[25,54]$ while analysis on Xoo strains originating from the Philippines yielded SNPs that did not overlap with any known resistance loci [24].

Although several BLB resistance genes have been discovered, their effectiveness depends upon pathogenic variability and the rate at which mutational adaptation overcomes resistance phenotypes. Identification of genes that confer resistance against different Xoo races is crucial in developing broad-scale resistant rice varieties. The discovery of novel resistance alleles will facilitate the development of new resistant cultivars. Here we aim to identify resistance loci and SNP markers in 222 accessions of rice germplasm that have been previously subject to whole genome sequencing (WGS) analysis by performing phenotypic assay of BLB against 20 Xoo isolates. Our work is intended to contribute to future BLB breeding programs both in Thailand and the rest of the world.

\section{Results}

\subsection{Phenotypic Screening}

Seedlings from our 222-accession (lines) panel were inoculated with 20 Xoo (bacterial leaf blight; BLB) isolates. From these, 19 isolates yielded a higher proportion of BLB susceptibility versus resistance across the 222 accessions (Table $\mathrm{S1} ; \mathrm{R}=5.6-32.4 \% ; \mathrm{S}=67.6-94.4 \%$ ). Only one isolate, 2 XOST2-2 yielded a greater number of resistant versus susceptible lines $(\mathrm{R}=62.1 \%: \mathrm{S}=37.9 \%)$ (Figure 1$)$. 


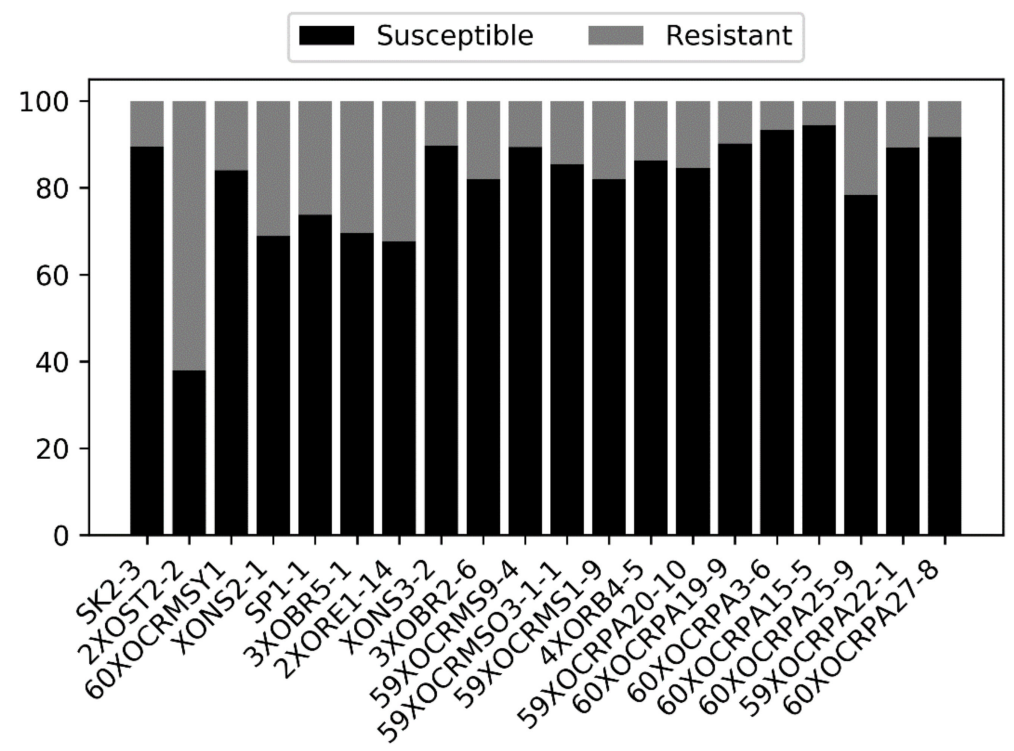

Figure 1. Percentage of susceptible versus resistant lines across 20 focal Xoo isolates (x-axis). Most rice accessions are predominantly susceptible to all but one Xoo isolate.

Leaf lesion length scores, resulting from BLB infection, showed marked variation according to Xoo strain across our 222-sample panel with mean values ranging from 5.79 (strain 2XOST2_2) to $13.93 \mathrm{~cm}$ (strain 60XOCRPA27_8) (Figure 2). Additionally, large error bars imply that lesion length varies substantially according to assayed rice variety.

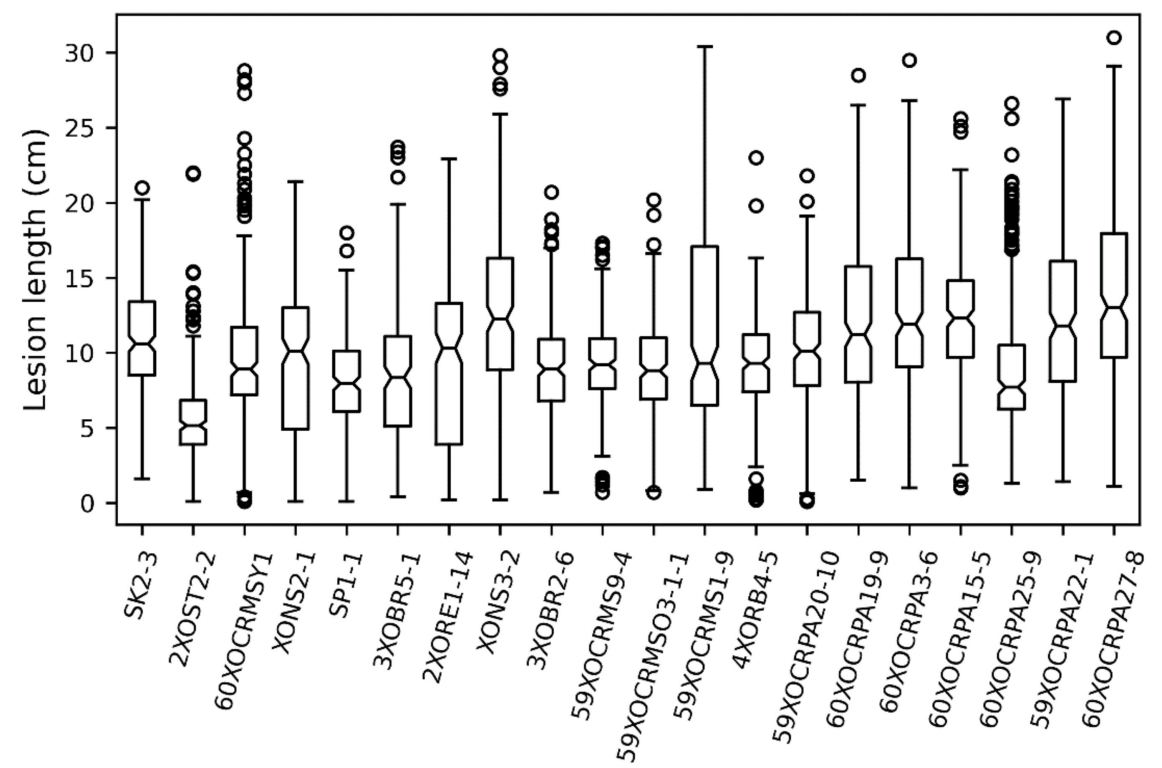

Figure 2. Leaf lesion length scores for BLB damage for rice panel cultivars across 20 focal Xoo isolates. Most Xoo isolates cause serious leaf damage.

\subsection{Population Structure of Rice Accessions}

After filtering our genomic data, we identified 142,362 high-quality SNPs across 222 rice accessions. Principal component analysis (PCA) indicates that samples comprise of three genomic clusters (Figure 3). PCA when combined with typed reference samples from the IRRI database (Figure S1), indicated that most Thai samples are predominantly of indica origin. Additionally, nine accessions are japonica origin (blue), while three accessions also cluster with IRRI-typed aus samples (orange). 


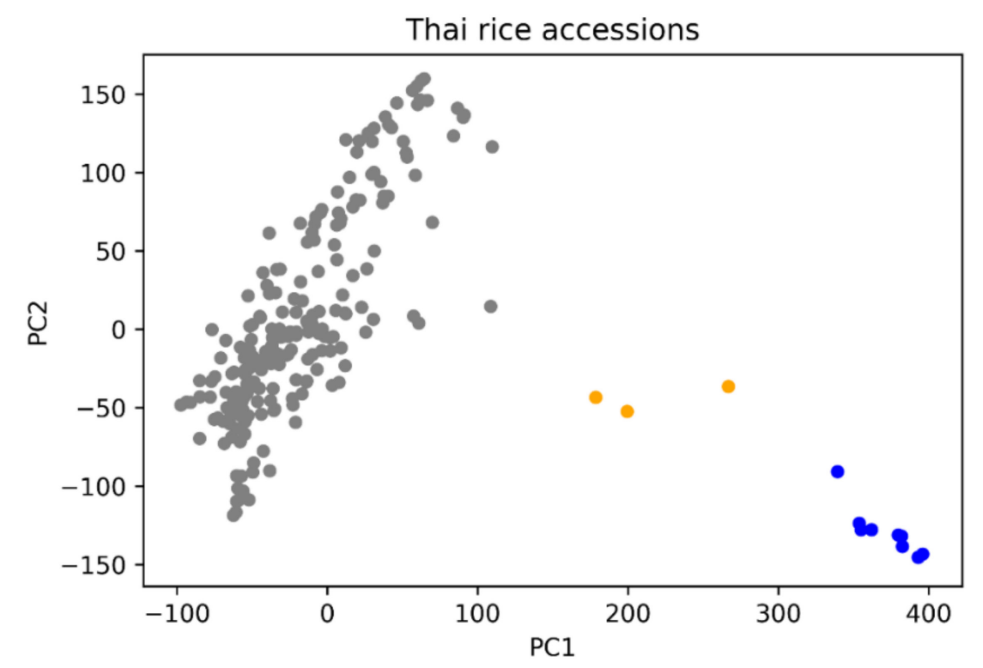

Figure 3. Principal component analysis of 222 accessions from our rice panel. Grey colour (PC1 <= 100) are indica varieties with a handful of japonica (blue) and aus / aro varieties (orange).

We then conducted linkage disequilibrium (LD) decay analyses to evaluate chromosomal signatures of recombination patterns (Figure 4). Mean LD decay values within intra-chromosomal distance bins drop below a threshold mean $\mathrm{r}^{2}$ value of 0.2 between 61-201 Kb across all 12 chromosomes. Signatures for all chromosomes appear similar except for chromosome 11 which has a markedly lower $(61 \mathrm{~Kb})$ threshold crossover point.

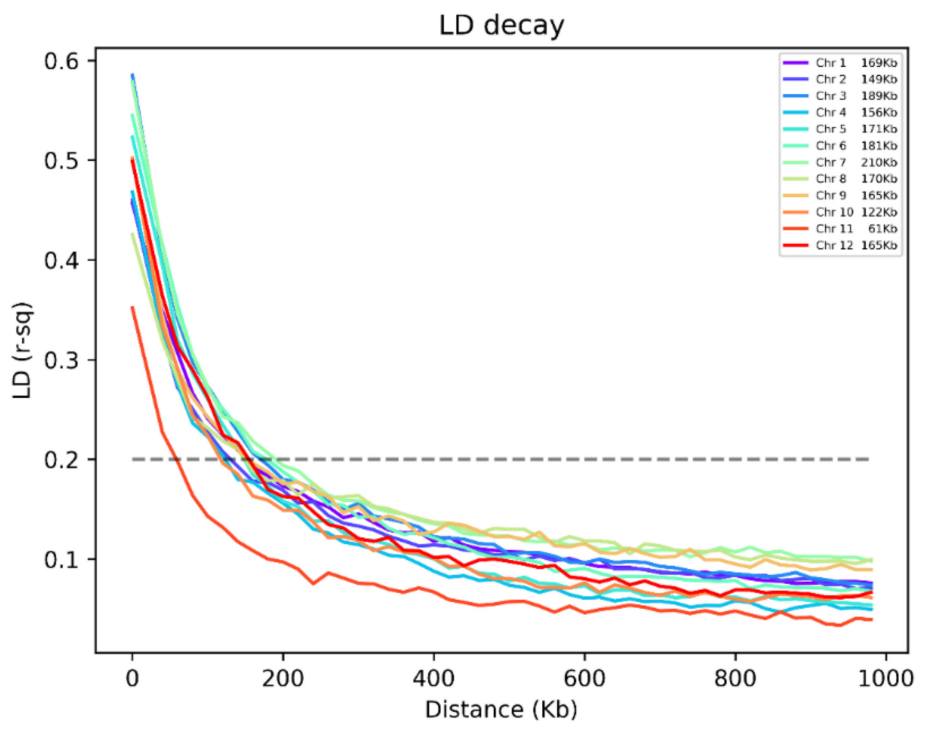

Figure 4. Linkage disequilibrium decay across 12 chromosomes in 222 O. sativa accessions. Mean LD decay ranges between $61-210 \mathrm{~Kb}$.

\subsection{GWAS Analysis}

We used genome-wide association study (GWAS) methods in TASSEL implementing an MLM model to identify loci associated with the resistance to Xoo isolates (Figure 5; Tables 1 and 2). Using false discovery rate (FDR) evaluation, we identified 406 significantly associated SNPs across chromosomes 1-6, 8-10 and 11. Of these, 207 were contained within 147 MSU designated gene regions across chromosomes 1-6, 8, 9 and 11, identified across seven Xoo strains (meaning 13 strains yielded no associated SNPs) (Table S2a,b). Additionally, we also employed bootstrap evaluation which proved more conservative, identifying 51 significantly associated SNPs within $26 \mathrm{MSU}$ annotated regions on chromosomes 3,5 and 11 . 
(a)

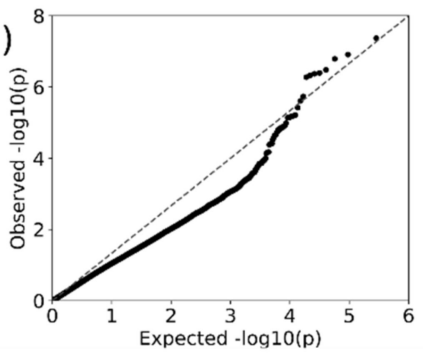

(b)

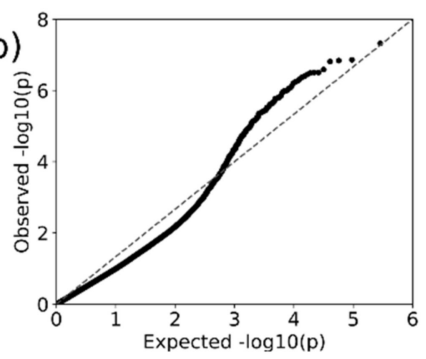

(c)
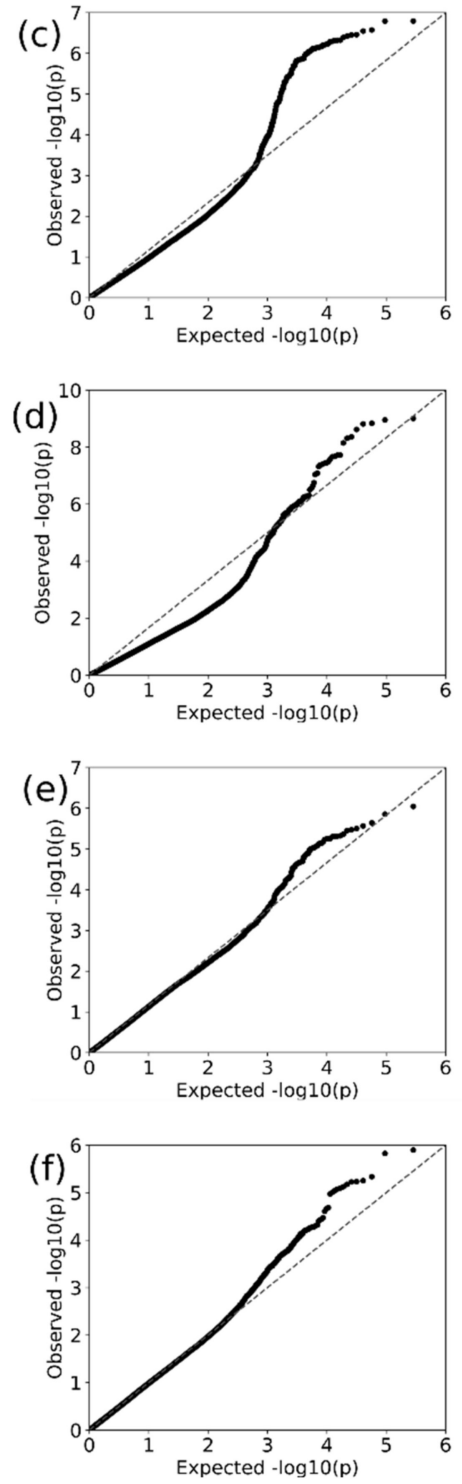
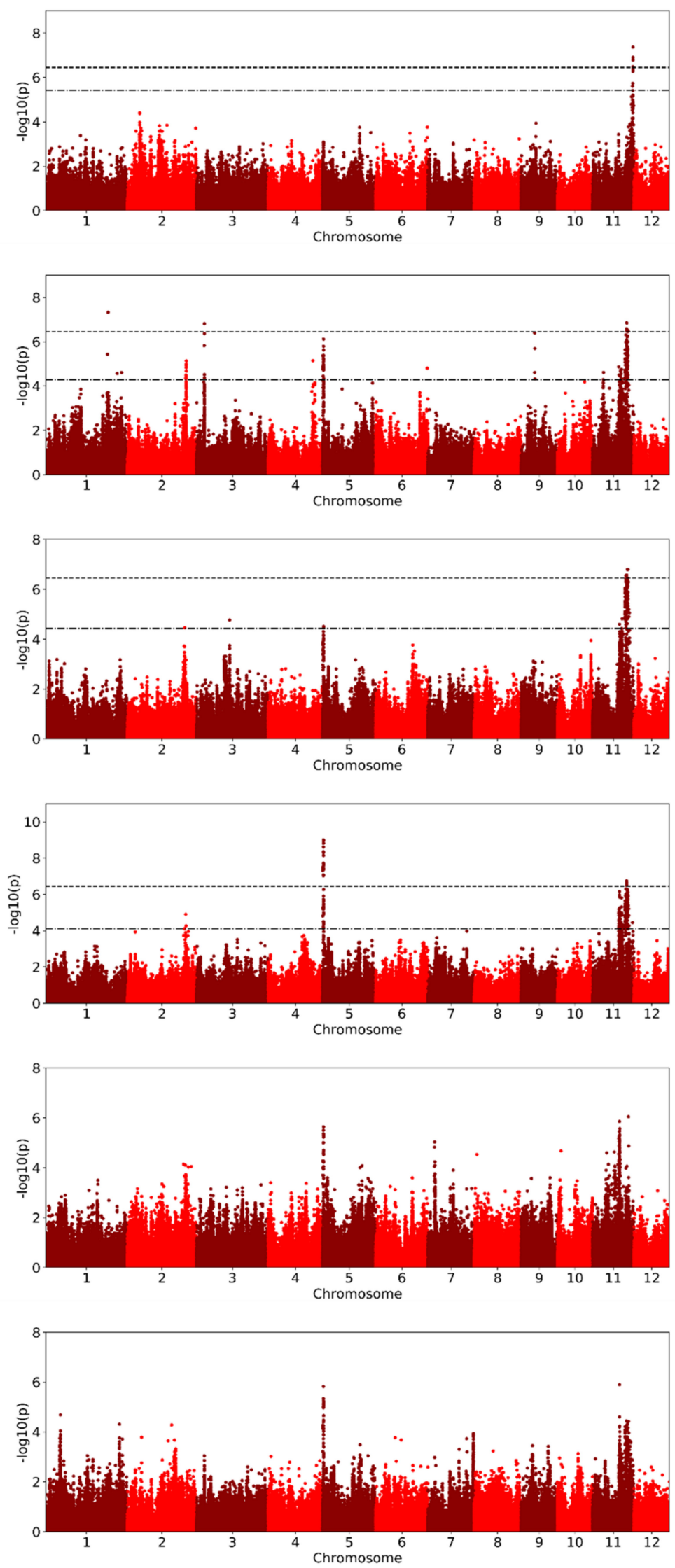

Figure 5. Cont. 

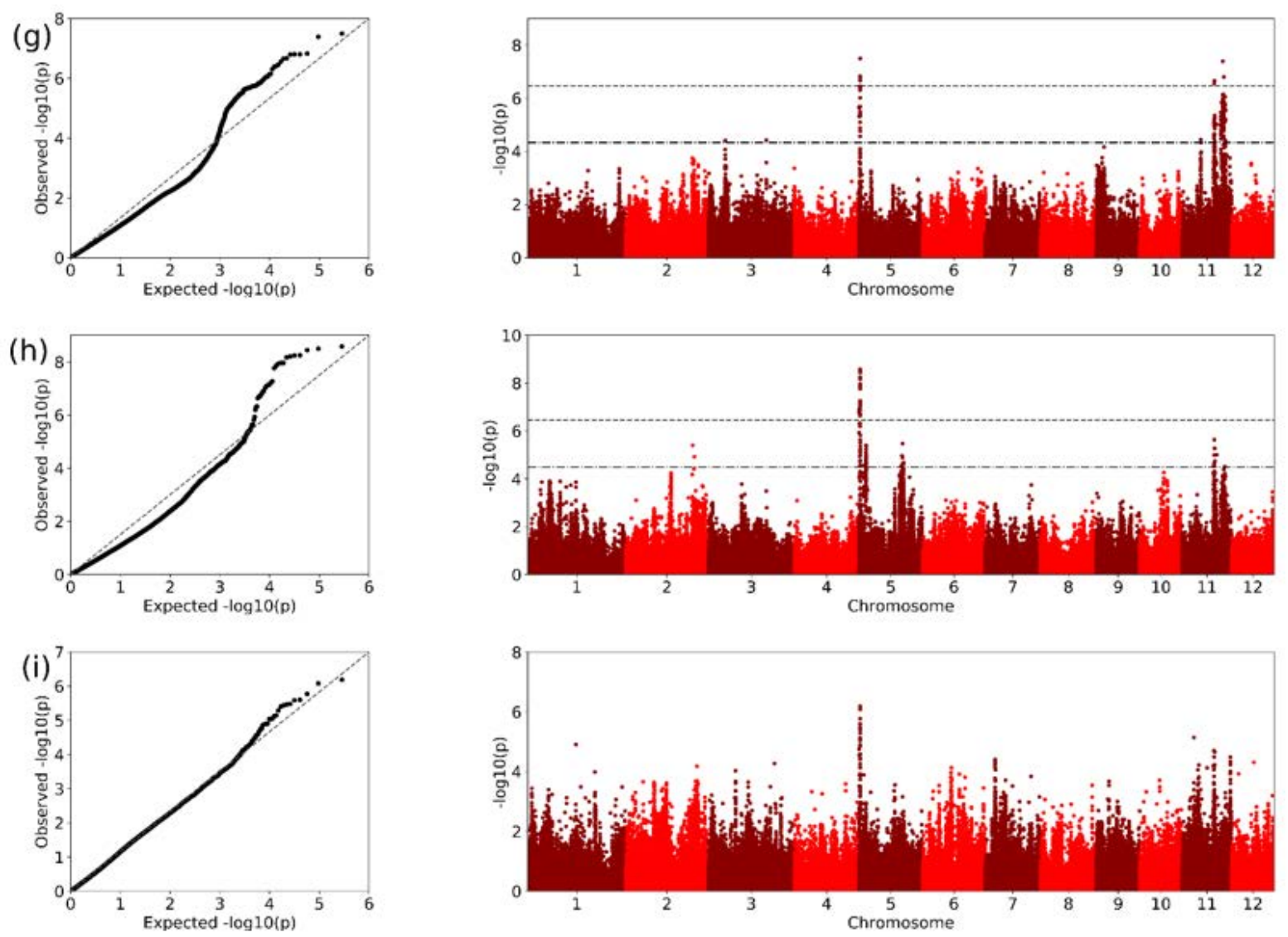

Figure 5. QQ and Manhattan plots from GWAS analyses highlighting significantly associated SNPs associating with bacterial leaf blight resistance for representative Xoo isolates. Figures (a-i), Xoo isolates: (a) 2XORE1-14; (b) 2XOST2-2; (c) 3XOBR2-6; (d) 4XORB4-5; (e) 59XOCRMS9-4; (f) 59XOCRMSO3-1-1; (g) 59XOCRPA20-10; (h) SP1-1; and (i) XONS3-2. Dot-dash and dashed lines represent FDR and bootstrap significance thresholds, respectively.

Table 1. SNPs associated with BLB resistance across seven Xoo isolates.

\begin{tabular}{|c|c|c|c|c|c|c|c|c|c|}
\hline Xoo Strain & Chr & $\begin{array}{l}\text { Position } \\
\text { (bp) }\end{array}$ & $\begin{array}{c}-\log 10 \\
\text { (p-Value) }\end{array}$ & $\begin{array}{c}\text { SNP } \\
\text { Genotypes }\end{array}$ & MAF (\%) & Marker $\mathbf{r}^{2}$ & $\begin{array}{c}\text { Genetic } \\
\text { Var }\end{array}$ & $\begin{array}{l}\text { Residual } \\
\text { Var }\end{array}$ & Heritability \\
\hline \multirow[t]{3}{*}{ SP1-1 } & 2 & 28895260 & 5.4 & $\mathrm{G}, \mathrm{T}$ & 11.11 & 0.12 & 3.77 & 7.15 & 0.35 \\
\hline & 5 & 372359 & 8.58 & AC & 8.78 & 0.19 & 3.77 & 7.15 & 0.35 \\
\hline & 11 & 17828845 & 5.63 & $\mathrm{C}, \mathrm{T}$ & 7.22 & 0.14 & 3.77 & 7.15 & 0.35 \\
\hline \multirow[t]{8}{*}{ 2XOST2-2 } & 1 & 35320544 & 7.33 & $\mathrm{C}, \mathrm{A}$ & 5.91 & 0.16 & 4.5 & 5.44 & 0.45 \\
\hline & 2 & 30161196 & 5.13 & $\mathrm{~T}, \mathrm{G}$ & 13.44 & 0.13 & 4.5 & 5.44 & 0.45 \\
\hline & 3 & 3379824 & 6.81 & $A, G$ & 5.52 & 0.16 & 4.5 & 5.44 & 0.45 \\
\hline & 4 & 30623393 & 5.15 & T,C & 6.15 & 0.11 & 4.5 & 5.44 & 0.45 \\
\hline & 5 & 457765 & 6.12 & $\mathrm{~T}, \mathrm{G}$ & 4.59 & 0.13 & 4.5 & 5.44 & 0.45 \\
\hline & 6 & 30380545 & 4.8 & $\mathrm{C}, \mathrm{A}$ & 6.19 & 0.1 & 4.5 & 5.44 & 0.45 \\
\hline & 9 & 10748870 & 6.4 & $\mathrm{~T}, \mathrm{G}$ & 7.04 & 0.14 & 4.5 & 5.44 & 0.45 \\
\hline & 11 & 22311354 & 6.86 & $\mathrm{~A}, \mathrm{G}$ & 8.72 & 0.14 & 4.5 & 5.44 & 0.45 \\
\hline \multirow[t]{4}{*}{ 3XOBR2-6 } & 2 & 29390164 & 4.46 & $\mathrm{C}, \mathrm{T}$ & 23.53 & $\begin{array}{l}0.14 \\
0.1\end{array}$ & 2.13 & 10.46 & 0.17 \\
\hline & 3 & 16299521 & 4.77 & $\mathrm{G}, \mathrm{C}$ & 5.97 & 0.1 & 2.13 & 10.46 & 0.17 \\
\hline & 5 & 463077 & 4.51 & $A, G$ & 7.43 & 0.09 & 2.13 & 10.46 & 0.17 \\
\hline & 11 & 23204208 & 6.8 & $\mathrm{C}, \mathrm{G}$ & 6.82 & 0.17 & 2.13 & 10.46 & 0.17 \\
\hline 2XORE1-14 & 11 & 27582018 & 7.37 & A,G & 30.48 & 0.17 & 7.03 & 12.16 & 0.37 \\
\hline \multirow[t]{3}{*}{ 4XORB4-5 } & 2 & 29791617 & 4.91 & $\mathrm{C}, \mathrm{A}$ & 16.48 & 0.11 & 3.55 & 7.82 & 0.31 \\
\hline & 5 & 461986 & 9.01 & $\mathrm{G}, \mathrm{A}$ & 4.5 & 0.2 & 3.55 & 7.82 & 0.31 \\
\hline & 11 & 22258758 & 6.75 & $\mathrm{G}, \mathrm{A}$ & 5.82 & 0.16 & 3.55 & 7.82 & 0.31 \\
\hline \multirow[t]{3}{*}{ 59XOCRPA20-10 } & 3 & 26795267 & 4.43 & $\mathrm{~T}, \mathrm{C}$ & 43.85 & 0.1 & 5.31 & 10.88 & 0.33 \\
\hline & 5 & 461986 & 7.5 & G.A & 4.5 & 0.17 & 5.31 & 10.88 & 0.33 \\
\hline & 11 & 22311354 & 7.39 & $A, G$ & 8.72 & 0.17 & 5.31 & 10.88 & 0.33 \\
\hline \multirow[t]{6}{*}{ 60XOCRMSY1 } & 1 & 33302431 & 5.17 & $\mathrm{~T}, \mathrm{C}$ & 6.53 & 0.1 & 10.28 & 9.19 & 0.53 \\
\hline & 3 & 16327075 & 4.54 & $\mathrm{~T}, \mathrm{G}$ & 7.27 & 0.11 & 10.28 & 9.19 & 0.53 \\
\hline & 5 & 461986 & 7.31 & G,A & 4.5 & 0.16 & 10.28 & 9.19 & 0.53 \\
\hline & 8 & 4006324 & 4.53 & $\mathrm{G}, \mathrm{A}$ & 11.56 & 0.09 & 10.28 & 9.19 & 0.53 \\
\hline & 10 & 15740836 & 4.7 & $A, G$ & 5.83 & 0.1 & 10.28 & 9.19 & 0.53 \\
\hline & 11 & 23617456 & 6.85 & $\mathrm{~A}, \mathrm{~T}$ & 9.9 & 0.15 & 10.28 & 9.19 & 0.53 \\
\hline
\end{tabular}


Table 2. Linkage clusters within $5 \mathrm{Mb}$ blocks across seven Xoo isolates. Clusters are delineated according to LD decay values for each chromosome.

\begin{tabular}{cccc}
\hline Chromosome & $\begin{array}{c}\text { Representative SNP } \\
\text { Position (bp) }\end{array}$ & Xoo Strain & $\begin{array}{c}\text { No. of Linkage } \\
\text { Blocks }\end{array}$ \\
\hline
\end{tabular}

35320544

2XOST2-2; 60XOCRMSY1

\section{XOBR2-6; 60XOCRMSY1} 59XOCRPA20-10

2XOST2-2

\section{MSU ID: Annotation}

LOC_Os01g57082: insulin-degrading enzyme, putative, expressed;

LOC_Os01g57590: expressed protein; LOC_Os01g59450: ZOS1-13-C2H2 zinc finger

protein, expressed; LOC_Os01g60440: HEAT repeat family protein,

putative, expressed; LOC_Os01g60660: methionyl-tRNA synthetase,

putative, expressed; LOC_Os01g61110: ulp1 protease family, C-terminal catalytic domain containing protein, expressed; LOC_Os01g61120: expressed protein; LOC_Os01g61335: expressed protein; LOC_Os01g61440: expressed protein;

LOC_Os01g61590: CAMK_CAMK_like.1-CAMK includes calcium/calmodulin dependent protein kinases, expressed;

LOC Os01g66490: no apical meristem protein, putative, expressed; LOC_Os01g66860: serine/threonine protein kinase, putative, expressed; LOC_Os01g70340: expressed protein; LOC_Os01g71960: endonuclease, putative, expressed;

LOC Os02g47310: Cyclopropane-fatty-acyl-phospholipid synthase, putative, expressed; LOC_Os02g48690: expressed protein; LOC_Os02g48730: rho GDP-dissociation inhibitor 1, putative, expressed; LOC_Os02g48830: microtubule associated protein, putative, expressed; LOC_Os02g48990: phosphatidylinositol

transfer, putative, expressed; LOC_Os02g49140: glycosyltransferase,

putative, expressed; LOC_Os02g49180: RNA polymerase subunit,

putative, expressed; LOC_Os02g49230: CCT/B-box zinc finger protein,

putative, expressed; LOC_Os02g49360: RNA methyltransferase domain-containing protein 2, putative, expressed;

LOC_Os03g06680: plant-specific domain TIGR01615 family protein, expressed LOC_Os03g06710: PPR repeat domain containing protein, putative, expressed;

LOC_Os03g12760: helix-loop-helix DNA-binding domain containing protein, expressed;

LOC_Os03g47380: expressed protein;

LOC_Os04g51690: glycosyl hydrolase family 47 domain contain protein, expressed; 
Table 2. Cont.

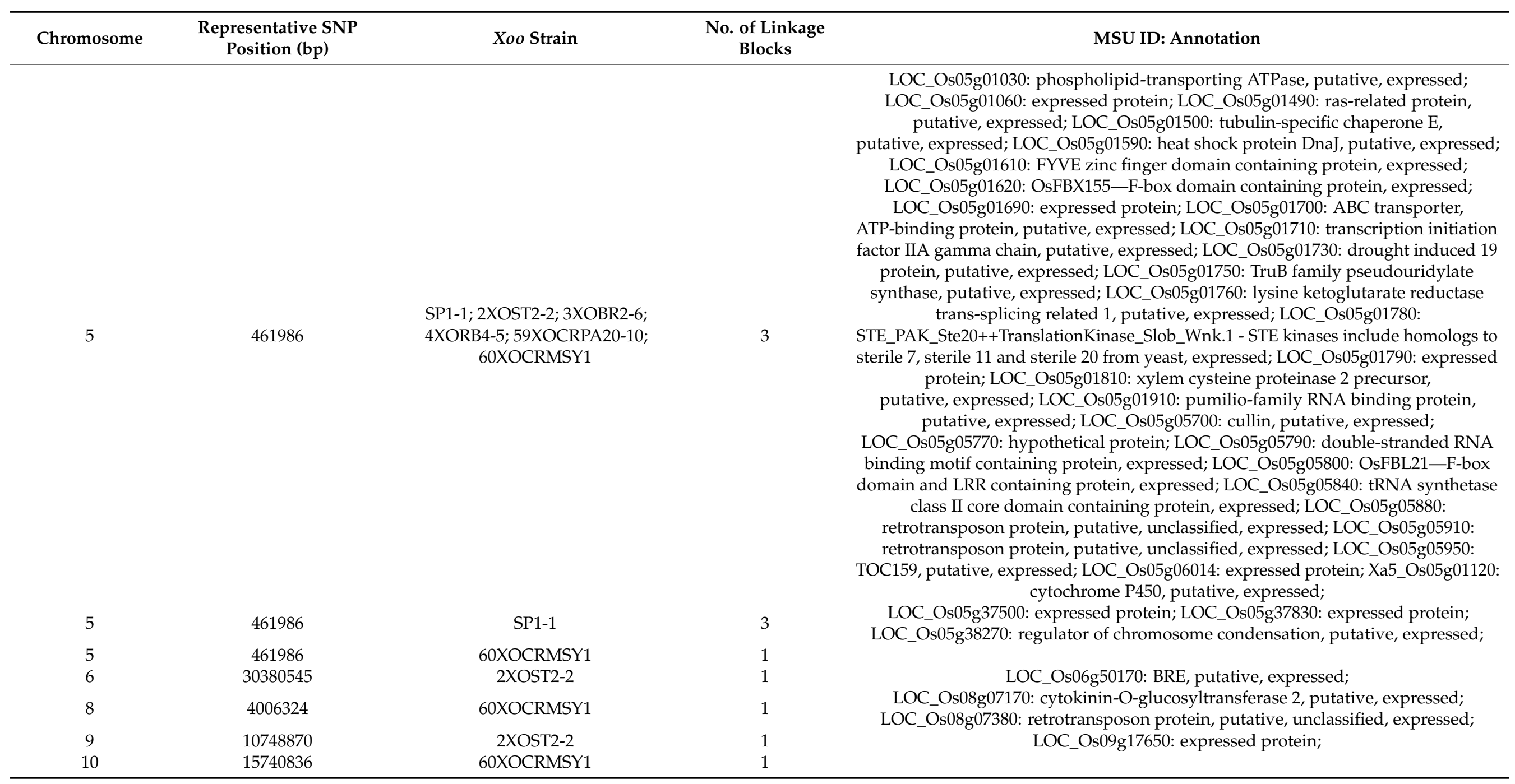


Table 2. Cont.

\begin{tabular}{cccc}
\hline Chromosome & $\begin{array}{c}\text { Representative SNP } \\
\text { Position (bp) }\end{array}$ & Xoo Strain & $\begin{array}{c}\text { No. of } \\
\text { Linkage } \\
\text { Blocks }\end{array}$ \\
\hline 11 & 22311354 & 2 XOST2-2.59XOCRPA20-10 & 3
\end{tabular}

of

ocks

OC Os11g13750: expressed protein:

LOC Os11g30370: OsSPL19 - SBP-box gene family member, expressed; LOC Os11g30560:

dehydrogenase/reductase, putative, expressed; LOC_Os11g30600: hypothetical protein;

LOC_Os11g30620: expressed protein; LOC_Os11g30740: transposon protein, putative, CACTA, En/Spm sub-class, expressed; LOC_Os11g30770: expressed protein; LOC_Os11g30790: expressed protein; LOC_Os11g30860: retrotransposon protein, putative, Ty3-gypsy subclass, expressed

LOC_Os11g30930: expressed protein; LOC_Os11g30940: retrotransposon protein, putative,

unclassified, expressed; LOC Os11g30960: retrotransposon protein, putative, unclassified, expressed;

LOC_Os11g31050: retrotransposon protein, putative, unclassified, expressed; LOC_Os11g31090:

transferase family protein, putative, expressed; LOC_Os11g31500: ATP binding protein, putative, expressed; LOC_Os11g31620: OsFBL55-F-box domain and LRR containing

protein, expressed; LOC_Os11g31650: expressed protein; LOC_Os11g31670: retrotransposon protein, putative, unclassified, expressed; LOC_Os11g31690: expressed protein; LOC_Os11g31950: expressed

protein; LOC_Os11g32210: jacalin-like lectin domain containing protein, expressed;

LOC_Os11g32320: CCB1, putative, expressed; LOC_Os11g32340: hypothetical protein;

LOC_Os11g32360: expressed protein; LOC_Os11g32369: expressed protein; LOC_Os11g32390: expressed protein; LOC_Os11g32410: expressed protein; LOC_Os11g32530: retrotransposon protein, putative, unclassified, expressed; LOC_Os11g32570: expressed protein; LOC_Os11g33190: OsFBX422 - F-box domain containing protein, expressed; LOC_Os11g35870: RWD domain containing

protein, expressed; LOC_Os11g36050: prefoldin subunit, putative, expressed; LOC_Os11g36060: THUMP domain-containing protein, putative, expressed; LOC_Os11g36070: expressed protein; LOC_Os11g36090: receptor kinase, putative, expressed; LOC_Os11g36140: receptor-like protein kinase 2 precursor, putative, expressed; LOC_Os11g36180: receptor kinase, putative, expressed; LOC_Os11g36340: lymphoid organ expressed yellow head virus receptor protein, putative, expressed; LOC_Os11g36350: OsFBDUF50-F-box and DUF domain containing protein, expressed;

LOC Os11g36390: RFC1 - Putative clamp loader of PCNA, replication factor C subunit 1, expressed; LOC_Os11g37000: heat shock protein DnaJ, putative, expressed; LOC_Os11g37090: pumilio-family RNA binding repeat domain containing protein, expressed; LOC_Os11g37100: expressed protein; LOC_Os11g37130: mttA/Hcf106 family protein, putative, expressed; LOC_Os11g37140: expressed protein; LOC_Os11g37260: SEY1, putative, expressed; LOC_Os11g37300: OsFBDUF53-F-box and DUF domain containing protein, expressed; LOC_Os11g37330: pentatricopeptide repeat domain containing protein, putative, expressed; LOC Os11g37510: ribosomal protein L4, putative, expressed; LOC Os11g37670: expressed protein; LOC_Os11g37680: expressed protein; LOC_Os11g37690: TBC domain containing protein, expressed; LOC_Os11g37700: pleiotropic drug resistance protein, putative, expressed; LOC_Os11g37730: glutathione S-transferase, N-terminal domain containing protein, expressed; LOC_Os11g37740: stripe rust resistance protein Yr10, putative, expressed; 
Table 2. Cont.

\begin{tabular}{cccc}
\hline Chromosome & $\begin{array}{c}\text { Representative SNP } \\
\text { Position (bp) }\end{array}$ & Xoo Strain & $\begin{array}{c}\text { No. of Linkage } \\
\text { Blocks }\end{array}$ \\
\hline
\end{tabular}

Blocks

MSU ID: Annotation

LOC_Os11g37860: stripe rust resistance protein Yr10, putative, expressed; LOC_Os11g37870: stripe rust resistance protein Yr10, putative, expressed;

LOC_Os11g37890: NAD dependent epimerase/dehydratase family protein, putative, expressed; LOC_Os11g37960: WIP4-Wound-induced protein precursor, expressed; LOC_Os11g38010: targeting protein for Xklp2,

putative, expressed; LOC_Os11g38020: GTPase of unknown function domain containing protein, putative, expressed; LOC_Os11g38040: expressed protein LOC_Os11g38050: phosphoesterase family protein, putative, expressed; LOC_Os11g38140: OsFBDUF58-F-box and DUF domain containing protein, expressed; LOC Os11g38270: hypothetical protein; LOC Os11g38620: expressed protein; LOC_Os11g38630: expressed protein; LOC_Os11g38640:

P1-1; 2XOST2-2; 3XOBR2-6

2XORE1-14; 4XORB4-5; 59XOCRPA20-10; 60XOCRMSY1 expressed protein; LOC_Os11g38670: DEAD-box ATP-dependent RNA helicase, putative, expressed; LOC_Os11g38800: zinc finger family protein,

putative, expressed; LOC_Os11g38810: mannose-6-phosphate isomerase, putative, expressed; LOC_Os11g38870: helix-loop-helix DNA-binding domain containing protein, expressed; LOC_Os11g38900: histone-lysine

$\mathrm{N}$-methyltransferase, H3 lysine-9 specific SUVH1, putative, expressed;

LOC_Os11g38970: expressed protein; LOC_Os11g39360: pentatricopeptide repeat domain containing protein, putative, expressed; LOC_Os11g39540: 14-3-3 protein putative, expressed; LOC_Os11g39650: WD domain, G-beta repeat domain

containing protein, expressed; LOC Os11g40200: expressed protein

LOC_Os11g40590: DUF1399 containing protein, putative, expressed; LOC_Os11g40840: receptor-like protein kinase 2 precursor, putative, expressed; LOC Os11g44910: DEAD-box ATP-dependent RNA helicase, putative, expressed; LOC_Os11g45290: retrotransposon protein, putative, unclassified, expressed;

LOC_Os11g45580: embryogenesis transmembrane protein, putative, expressed; LOC_Os11g45590: transposon protein, putative, CACTA, En/Spm sub-class, expressed; LOC_Os11g45620: rust-resistance protein Lr21, 
Only one identified SNP, at LOC_Os05g01710, is situated within a known BLB resistance gene (Xa5) within the genome. However, $21 \mathrm{MSU}$ designated genes are located within LD decay thresholds of previously cloned $R$ genes on chromosomes 5 and 11 . A further $127 \mathrm{MSU}$ genes are found external to the identified LD blocks surrounding $R$ genes on chromosomes 1-6, 8, 9 and 11. Furthermore, our analyses identified SNPs within MSU annotated genes on chromosomes 1, 2, 5 and 11 that have GOSLIM classifications indicating they are functional regions involved in stress responses to external stimuli (Table S2). SNPEFF analyses indicated that four of these annotated genes feature alternative alleles that possess mutations predicted to confer "moderate" (i.e., functional) influence on their respective gene sequences (Table S3). Additionally, a further 199 significant loci were identified outside of the designated MSU gene loci on chromosomes 1-3, 5 and 8-11. Mostly these are on chromosomes 5 and 11 and generally constitute clusters of SNPs occupying regions where identified MSU genes are concentrated.

Figure 6 shows the positions of 10 identified MSU genes on chromosome 11 within the 17-29 Mb region, including two genes (LOC_Os11g31620 and LOC_Os11g32210) that are entirely isolated from known $R$ gene positions. Significantly associated SNPs largely appear within two clusters where the 10 MSU genes are predominantly situated. In general, these genes harbour haplotypes (Figure 7) that confer significantly different levels of BLB susceptibility (Figure 8; Table 3). We highlight the positions of further stress response genes (including other MSU genes containing significantly associated SNPs) in Figure S2.

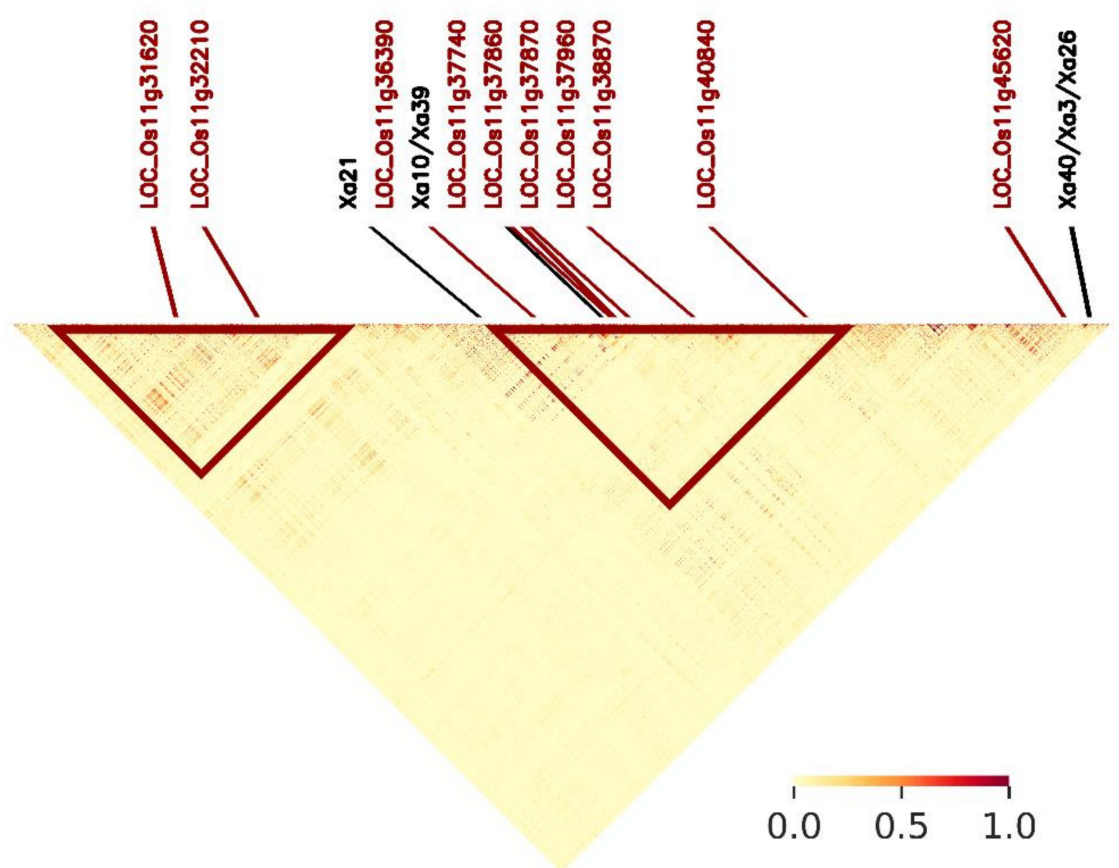

Figure 6. Linkage disequilibrium (LD) heatmap for chromosome 11 (region 17-29Mb) indicating chromosomal locations of six previously mapped $\mathrm{R}(\mathrm{X} a)$ genes and ten MSU annotated genes (LOC_Os prefix) that contain significantly associated SNPs highlighted by GWAS that are: (i) greater than $\mathrm{LD}$ decay threshold $(61 \mathrm{~Kb})$ away from $R$ genes; and (ii) described by Go categorizations as having stress response functionality. A lack of red areas on the heatmap indicates the generally low levels of LD for this chromosome. Red triangles indicate densely clustered regions of significantly associated SNPs. Pointers show map positions (bottom) and relative position on chromosome within the region (top). 
(a)

\begin{tabular}{|c|c|c|c|c|c|c|}
\hline Loc_Os11g31620 & 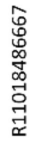 & $\underset{\Xi}{\bar{E}}$ & 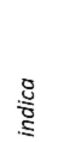 & 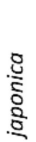 & 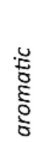 & $\begin{array}{l}\overline{\text { गु }} \\
\stackrel{0}{\circ}\end{array}$ \\
\hline Hap. 1 & G & 9.882 & 195 & 9 & 4 & 208 \\
\hline Hap. 2 & A & 6.079 & 14 & 0 & 0 & 14 \\
\hline
\end{tabular}

(b)

\begin{tabular}{|c|c|c|c|c|c|c|}
\hline Loc_Os11g32210 & 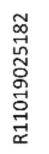 & $\underset{\Xi}{\bar{E}}$ & $\begin{array}{l}\stackrel{\mathscr{J}}{\bar{t}} \\
\stackrel{5}{5}\end{array}$ & 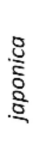 & 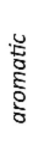 & 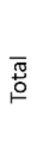 \\
\hline Hap. 1 & $\mathrm{C}$ & 9.834 & 187 & 8 & 2 & 197 \\
\hline Hap. 2 & A & 5.084 & 22 & 2 & 1 & 25 \\
\hline
\end{tabular}

(c)

\begin{tabular}{|c|c|c|c|c|c|c|c|c|c|c|}
\hline Loc_Os11g36390 & 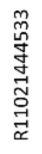 & 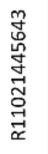 & 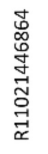 & 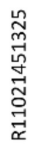 & 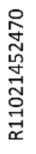 & 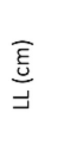 & 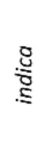 & 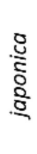 & 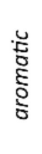 & $\begin{array}{l}\overline{\widetilde{J}} \\
0\end{array}$ \\
\hline Hap. 1 & G & G & G & G & A & 9.121 & 196 & 8 & 4 & 208 \\
\hline Hap. 2 & $\mathrm{C}$ & A & C & A & G & 4.681 & 12 & 0 & 0 & 12 \\
\hline Hap. 3 & C & A & C & A & A & 15.0 & 1 & 0 & 0 & 1 \\
\hline Hap. 4 & $\mathrm{C}$ & A & G & A & G & 1.62 & 0 & 1 & 0 & 1 \\
\hline
\end{tabular}

(e)

\begin{tabular}{|c|c|c|c|c|c|c|}
\hline Loc_Os11g37860 & 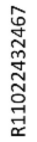 & $\underset{\underline{\Xi}}{\bar{E}}$ & 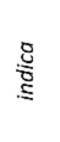 & 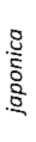 & 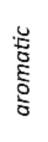 & $\begin{array}{l}\overline{\widetilde{J}} \\
\stackrel{0}{\circ}\end{array}$ \\
\hline Hap. 1 & $\mathrm{G}$ & 8.706 & 197 & 6 & 4 & 207 \\
\hline Hap. 2 & A & 4.239 & 12 & 3 & 0 & 15 \\
\hline
\end{tabular}

(g)

\begin{tabular}{|c|c|c|c|c|c|c|}
\hline Loc_Os11g37960 & 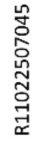 & 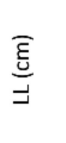 & 莺 & 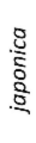 & 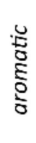 & $\begin{array}{l}\overline{\mathbb{J}} \\
\stackrel{0}{\circ}\end{array}$ \\
\hline Hap. 1 & $\mathrm{~A}$ & 9.159 & 197 & 9 & 4 & 210 \\
\hline Hap. 2 & G & 3.876 & 12 & 0 & 0 & 12 \\
\hline
\end{tabular}

(i)

\begin{tabular}{|c|c|c|c|c|c|c|}
\hline Loc_Os11g40840 & 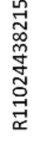 & $\underset{\Xi}{\bar{E}}$ & 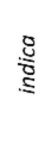 & 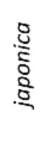 & 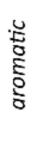 & $\begin{array}{l}\overline{\widetilde{\pi}} \\
\stackrel{0}{\circ}\end{array}$ \\
\hline Hap. 1 & $T$ & 9.522 & 188 & 8 & 4 & 200 \\
\hline Hap. 2 & A & 6.018 & 21 & 1 & 0 & 22 \\
\hline
\end{tabular}

(d)

\begin{tabular}{|c|c|c|c|c|c|c|c|}
\hline Loc_Os11g37740 & 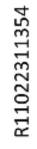 & 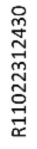 & $\frac{\overline{\underline{E}}}{\Xi}$ & 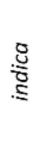 & 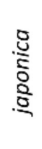 & 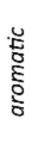 & $\begin{array}{l}\overline{\widetilde{7}} \\
\stackrel{\circ}{\circ}\end{array}$ \\
\hline Hap. 1 & A & G & 9.292 & 193 & 6 & 4 & 203 \\
\hline Hap. 2 & G & $T$ & 4.426 & 16 & 3 & 0 & 19 \\
\hline
\end{tabular}

(f)

\begin{tabular}{|c|c|c|c|c|c|c|}
\hline Loc_Os11g37870 & 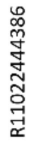 & $\underset{\underline{\Xi}}{\bar{E}}$ & 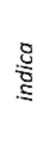 & 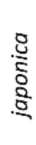 & $\begin{array}{l}\text { :ै } \\
\text { है } \\
\text { 이 }\end{array}$ & $\begin{array}{l}\overline{\widetilde{\sigma}} \\
\stackrel{0}{\circ}\end{array}$ \\
\hline Hap. 1 & $\mathrm{G}$ & 9.159 & 197 & 9 & 4 & 210 \\
\hline Hap. 2 & $\mathrm{C}$ & 3.876 & 12 & 0 & 0 & 12 \\
\hline
\end{tabular}

(h)

\begin{tabular}{|c|c|c|c|c|c|c|}
\hline Loc_Os11g38870 & 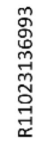 & 嘼 & 总 & $\begin{array}{l}\text { व } \\
0 \\
0\end{array}$ & $\begin{array}{l}\text { है } \\
\text { है } \\
\frac{5}{\delta}\end{array}$ & 嵒 \\
\hline Hap. 1 & $T$ & 9.159 & 197 & 9 & 4 & 210 \\
\hline Hap. 2 & A & 3.876 & 12 & 0 & 0 & 12 \\
\hline
\end{tabular}

(j)

\begin{tabular}{|c|c|c|c|c|c|c|}
\hline Loc_Os11g45620 & 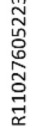 & $\underset{\Xi}{\bar{E}}$ & $\begin{array}{l}\stackrel{g}{\tilde{y}} \\
\stackrel{5}{5}\end{array}$ & 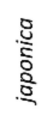 & $\begin{array}{l}\text {. } \\
\text { है } \\
\text { है }\end{array}$ & $\begin{array}{l}\overline{\widetilde{J}} \\
\text { 。 }\end{array}$ \\
\hline Hap. 1 & $T$ & 11.897 & 128 & 6 & 1 & 135 \\
\hline Hap. 2 & C & 5.29 & 81 & 3 & 3 & 87 \\
\hline
\end{tabular}

Figure 7. Tabular representation of alternative haplotypes determined by occurrence of significantly associated SNPs identified by GWAS analysis. (a-j) indicates specified MSU annotated genes. 

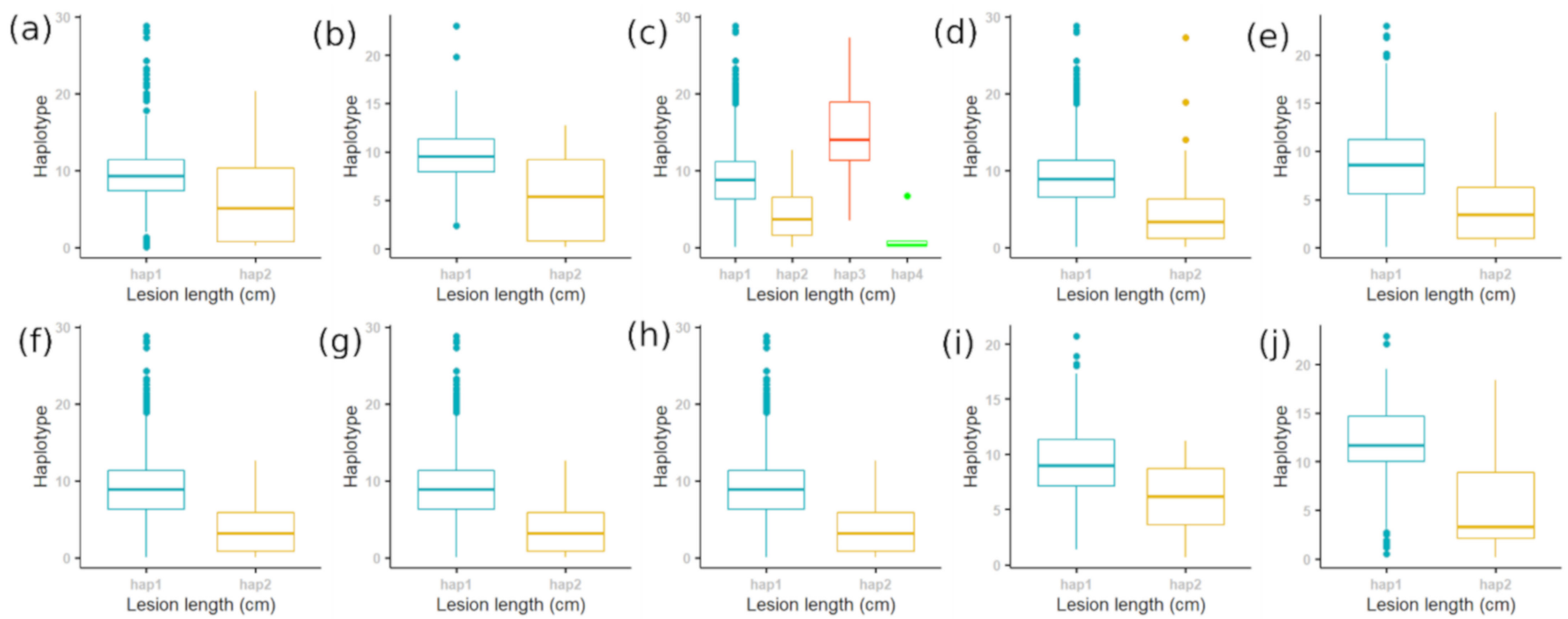

Figure 8. Boxplots indicating phenotypic responses in BLB resistance among rice accessions featuring alternative haplotypes determined by occurrence of significantly associated SNPs identified by GWAS analysis. (a) LOC_Os11g31620;
(b) LOC_Os11g32210;
(c) LOC_Os11g40840;
(d) LOC_Os11g45620;
(e) LOC_Os11g37860;
(f) LOC_Os11g37870;
(g) LOC_Os11g37960; (h) LOC_Os11g38870; (i) LOC_Os11g31620; and (j) LOC_Os11g31620.

Table 3. ANOVA results of BLB resistance assays among different haplotypes determined by presence/absence of significantly associated SNPs contained within MSU gene boundaries. Bold indicates significance while ${ }^{* *}$ indicates significance at the $<0.0001$ level.

\begin{tabular}{|c|c|c|c|c|c|}
\hline MSU Locus & $\begin{array}{l}\text { Haplotype } \\
\text { Comparison }\end{array}$ & Mean Diffs & $\begin{array}{c}\text { Lower CI } \\
(95 \%)\end{array}$ & $\begin{array}{c}\text { Upper CI } \\
(95 \%)\end{array}$ & Adjusted P \\
\hline LOC_Os11g31620 & Hap1-Hap2 & -3.803 & -5.44 & -2.167353 & $6.40 \mathrm{E}-06^{* * *}$ \\
\hline LOC_Os11g32210 & Hap1-Hap2 & -4.750 & -6.037 & -3.462886 & $0 * * *$ \\
\hline \multirow[t]{6}{*}{ LOC_Os11g36390 } & Hap1-Hap2 & -4.44 & -5.858 & -3.021265 & $0 * * *$ \\
\hline & Hap1-Нap3 & 5.879 & 1.129 & 10.62905 & $0.008 * *$ \\
\hline & Hap1-Hap4 & -7.501 & -12.251 & -2.75095 & $3 \mathrm{E}-04 * * *$ \\
\hline & Нар2-Нар3 & 10.319 & 5.383 & 15.253991 & $5 \mathrm{E}-07 * * *$ \\
\hline & Hap2-Hap4 & -3.061 & -7.997 & 1.873991 & 0.3812906 \\
\hline & Hap3-Hap4 & -13.38 & -20.081 & -6.678551 & $2 \mathrm{E}-06 * * *$ \\
\hline LOC_Os11g37740 & Hap1-Hap2 & -4.866 & -5.726 & -4.00688 & $0 * * *$ \\
\hline LOC_Os11g37860 & Hap1-Hap2 & -4.467 & -5.671 & -3.263031 & $0 * * *$ \\
\hline LOC_Os11g37870 & Hap1-Hap2 & -5.283 & -6.363 & -4.202503 & $0 * * *$ \\
\hline LOC_Os11g37960 & Hap1-Hap2 & -5.283 & -6.363 & -4.202503 & $0 * * *$ \\
\hline LOC_Os11g38870 & Hap1-Hap2 & -5.283 & -6.363 & -4.202503 & $0 * * *$ \\
\hline
\end{tabular}

Finally, significantly associated SNPs were found across seven Xoo isolates, meaning 13 Xoo isolates did not yield significantly associated loci. Individual MSU gene regions were found to contain significantly associated SNPs (FDR threshold) across a maximum of six Xoo isolates (Tables S2 and S3). Moreover, many MSU regions only contained significantly associated SNPs (FDR threshold) across a single Xoo isolate (e.g., on chromosomes 1 and 2). Xoo strains SP1-1, 2XOST2-2, 3XOBR2-6, 4XORB4-5, 59XOCRPA20-10 and 60XOCRMSY1 yielded between 4-79 MSU gene regions containing significant SNPs with 1-5 SNPs per gene region (Table 4). 
Table 4. Summary table of MSU designated gene regions containing significantly associated SNPs according to Xoo strain inoculation.

\begin{tabular}{cccc}
\hline Xoo Strain & $\begin{array}{c}\text { No. of MSU } \\
\text { Genes Affected }\end{array}$ & $\begin{array}{c}\text { Min. No. SNPs } \\
\text { Per Gene }\end{array}$ & $\begin{array}{c}\text { Max. No. SNPs } \\
\text { Per Gene }\end{array}$ \\
\hline SP1-1 & 33 & 1 & 4 \\
2XOST2-2 & 62 & 1 & 4 \\
3XOBR2-6 & 44 & 1 & 5 \\
2XORE1-14 & 4 & 1 & 3 \\
4XORB4-5 & 79 & 1 & 4 \\
59XOCRPA20-10 & 54 & 1 & 3 \\
60XOCRMSY1 & 66 & 1 & 3 \\
\hline
\end{tabular}

\section{Discussion}

Since the 1970s, bacterial leaf blight has become one of the biggest rice production concerns in Asia. The problem seemingly exacerbated by modern agricultural techniques combined with anthropogenic environmental (e.g., climate) change. We conducted GWAS on a 222-accession panel of mostly Thai rice cultivars alongside some additional global varieties and comprising principally indica varieties, infected by representative Thai strains of $20 \mathrm{Xoo}$ isolates to analyse the genetic basis of bacterial leaf blight (BLB) resistance in rice. We detected regions of significantly associated SNPs associated with Xoo resistance on chromosomes 1-6 and 8-11 (Table S2).

On chromosome 11, we identified hotspot regions that are substantial chromosomal distances away from previously reported $R$ resistance genes suggesting the potential discovery of novel resistance genes against BLB. Notably, ten of these MSU designated genes highlighted on chromosome 11 have GOSLIM classifications indicating that these regions are involved in stress responses from external environmental stimuli. In total, 241 of 406 significantly associated SNPs found across the genome are present on chromosome 11, mostly clustered on the $17-29 \mathrm{Mb}$ region.

Rice accessions carrying the closely linked $\mathrm{Xa4}$ [60] and Xa3/Xa26 genes on chromosome 11 exhibit broad resistance to numerous Xoo strains (NB these are also close to the more strain specific gene, Xa43). We did not find significant SNPs present within these gene regions although we identified significant SNPs within calculated linkage disequilibrium distance including within a nearby stress response gene (LOC_Os11g45620; Figure 6). It is also notable that our data do not corroborate findings from analyses of Philippines Xoo strains which reported many SNPs on chromosomes 6, 9 and 12 [24] (although the authors also reported associated SNPs on chromosome 11).

In addition to findings on chromosome 11, chromosome 5 features a cluster of significant SNPs close to the previously identified $R$ gene, $x a 5$ [61], as well as a chromosomally distinct MSU designated gene associated with stress responses (LOC_Os05g05800; Figure S2b). Chromosome 5 features 92 of 406 significantly associated SNPs mostly clustered on the $0-6 \mathrm{Mb}$ region. Chromosomes 1 and 2 also have clusters of significant SNPs including those from stress response genes. Previously, $R$ genes have not been cloned on chromosomes 1 and 2. Chromosomes 1 and 2 feature 52 of the 406 significant SNPs across the chromosome meaning that chromosomes 1,2,5 and 11 account for $c a .94 .8 \%$ of identified loci. Overall, it should also be noted that we further checked and failed to find identified significant SNPs located within 22 SWEET gene regions known for associated susceptibility to Xoo (e.g., [62]).

In general, SNPs associated with BLB resistance appear contingent on the inoculated Xoo strain with only seven out of 20 strains eliciting significant loci from GWAS. Such race specificity has been noted for other reported R genes and QTLs $[30,63,64]$. This also holds true among the seven Xoo strains that elicited positive results, with efficacious loci often showing responses across only 2-3 strains (although SNPs on chromosome 11 are often associated with $\geq 5$ Xoo strains, while SNPs on chromosomes 1 and 2 have single strain associations; Table S2). When considering our GWAS experiments were conducted against 
a large sample of Thai endemic Xoo strains $(n=20)$, this suggests that broad-scale effect genes may be generally elusive among global rice genotypes or only found at select loci (certainly among indica varieties).

These results concur with those of previous studies [24,54] in suggesting that broadscale, multi Xoo strain resistance may be difficult to identify in rice. One interesting point raised by Zhang et al. [54] is that BLB resistance may be particularly robust in indica varieties due to their tropical origins where outbreaks are most common due to favourable environmental factors for the survival, propagation, and infection of Xoo [2,63]. While our data primarily focusses on indica varieties, there is no obvious pattern suggesting that BLB resistance is more prevalent among our indica varieties when compared with japonica (Figure 7).

Our results, where significant SNPs were identified at best across six Xoo strains, combined with other studies suggest that the identification of 'silver bullet', broad-scale genomic resistance solutions to BLB pathogenicity is likely to prove evasive. Therefore, the most likely practical solutions should entail the development of multi-locus resistance rice varieties that provide greater antagonism to adaptive mutational responses across a range of Xoo strains that would be predicted to more readily undermine resistance in single-locus resistant varieties. Moreover, the tailoring of strategies that employ specific rice cultivars in explicit geographic regions with respect to localised presence of particular Xoo strains may be the optimal solution. From our data, the majority of significant loci that yield significant results against the most Xoo strains (typically $\geq 5$; Table S2), are located in a cluster on chromosome 11 (from ca. 20.9 to $25 \mathrm{Mb}$ ) surrounding (either closely or at relatively large distances) around the resistance genes, Xa10/Xa39 and Xa21 (Figure 6). There is also a dense cluster of identified genes at around ca. 17.4 to $19.7 \mathrm{Mb}$ that are associated with only a few Xoo strains. Notably, both these regions contain GOSLIM classification stress response loci.

\section{Materials and Methods}

\subsection{Plant Materials}

A panel of rice germplasm consisting of 222 accessions previously subject to whole genome sequencing featuring a full reference database of variant SNP calls against the MSU rice reference genome (ver. 7; http:/ / rice.plantbiology.msu.edu/pub/data/Eukaryotic_ Projects/o_sativa/annotation_dbs/pseudomolecules/version_7.0/; accessed 10 April 2020).

\subsection{BLB Screening}

Our rice germplasm panel accessions were evaluated for BLB resistance against 20 different Thai Xoo isolates selected to comprehensively represent genetic and phenotypic variation of Xoo in Thailand (Table S1). Our rice germplasm panel accessions were evaluated for BLB resistance against 20 different Thai Xoo isolates selected to comprehensively represent genetic and phenotypic variation of Xoo in Thailand. The rice varieties IR24 and PYBB36 were used as susceptible and resistant standard checks, respectively. PYBB36 was developed by Rice Gene Discovery Unit (RGDU), Thailand, and is known to carry three BLB resistance genes, $x a 5, X a 21$, and $x a 33$. Bacterial inoculum were maintained on PSA (5 g peptone, $20 \mathrm{~g}$ sucrose, $3 \mathrm{~g}$ beef extract, and $15 \mathrm{~g}$ agar, adjusted to 1 litter with $\mathrm{dH}_{2} \mathrm{O}$ ) medium for $72 \mathrm{~h}$ at $28^{\circ} \mathrm{C}$ before application. The bacterial cells were suspended in sterile water at a density of $10^{9}$ cells $/ \mathrm{mL}$. Plants were grown under greenhouse condition at RGDU. The inoculation followed the clipping method outlined by Kauffman et al., [65]. For each accession ( $n=222)$, two almost fully expanded leaves from four replicate plants for each of 20 Xoo isolates ( $n=17,760$ experimental plants) were removed and measured for lesion length (LL) at 14 days after inoculation or after the susceptibility check was complete. Plants were evaluated for BLB resistance by measuring the length of lesions (LL) based on the Standard Evaluation System (SES) recommended by IRRI (Table S1). Lesion lengths $<5 \mathrm{~cm}$ were considered as resistant (R). $>5-10 \mathrm{~cm}$ were considered as moderately 
resistant (MR), $>10-15 \mathrm{~cm}$ were considered as moderately susceptible (MS), and $>15 \mathrm{~cm}$ were considered as susceptible (S).

\subsection{Estimation of Population Parameters}

We conducted Principal Component Analysis (PCA) to (i) understand the genetic structure among the rice accession panel, and (ii) integrate with representative data from the IRRI 3000 Rice Genomes Project (http:/ /iric.irri.org/resources/3000-genomes-project; accessed 11 March 2020) database, to establish what typed varieties our accession panel clusters against. Next, we conducted Linkage Disequilibrium (LD) assessment to evaluate the mean size of genomic linkage blocks within each chromosome. We thinned our VCF file in VCFTOOLS [66] so no SNPs were less than $1000 \mathrm{bp}$ apart in order that the dataset was computationally manageable. Pairwise linkage between all remaining loci within chromosomes were conducted using the R library LDheatmap [67]. Outputted results were then passed to custom PYTHON scripts for plotting by calculating mean LD within 100 bin divisions of total chromosome length.

\subsection{Genome-Wide Association Study (GWAS) Methods}

The association of SNP markers and bacterial leaf blight resistance was performed using TASSEL 5.0 [68]. A total number of 142,362 SNPs that met the filtering criteria (MAF $>0.5$ and missing data less than $30 \%$ ) were used as genotype data while lesion lengths determined from leaves inoculated by each of 20 Xoo isolates were used as phenotypic data. A PCA was conducted to assess population structure and a kinship (K) matrix was created using centred identity-by-state to determine the familial relatedness between rice accessions. A mixed linear model [69] was used for performing GWAS by incorporating the K matrix along with the first three PCs using TASSEL 5.0.

From Tassel outputs we produced PYTHON scripts to generate QQ-plots by plotting observed probabilities for each marker against the set of probabilities at which to evaluate the inverse distribution [70]. We also generated Manhattan plots to illustrate individual marker associations by plotting each marker against the negative logarithm of its GWAS-generated probability. For each plot we calculated the false discovery rate at $5 \%$ threshold [71] and the Bonferroni correction threshold also at 5\% [72]. In order to better visualize and examine the identified SNPs and genomic regions from our GWAS analyses we used customized PYTHON programming to integrate our GWAS results against the MSU pseudomolecule genomic regions database hosted by the Rice Genome Annotation Project [73]. Our program (https:/ / github.com/ctdarwell/TASSELmanip) facilitates clear presentation of all identified significantly associated SNPs (using FDR and Bonferroni) within a GWAS analysis, permitting visualisation of which significant MSU genomic regions are identified for each inspected Xoo strain allowing easy assessment of potential loci that may confer broad multi-strain resistance potential. Main results are displayed in tabular form while other output files are generated, including a table that indicates MSU annotated function of all genomic regions containing significantly associated SNPs.

\subsection{Additional Genomic Evaluation}

To evaluate whether the significantly associated SNPs that we identified are likely to have independent functional contribution to resistance phenotypes against bacterial leaf blight, we conducted several further analyses. First, GOSLIM (http:/ / rice.plantbiology. msu.edu/downloads_gad.shtml; accessed 2 July 2020) annotations for genes containing significant loci identified by GWAS were searched to identify loci that have potential functional influence on bacterial leaf blight resistance. In particular, we focused on loci that are further away than the average LD influence block size (according to an $\mathrm{r}^{2}$ criterion of 0.2 ) for a given chromosome, in order to highlight regions that may potentially harbour novel genes underpinning BLB resistance. Further, we only selected loci whose GOSLIM annotations are categorized as stress response genes that therefore most likely predict novel candidate resistance genes. Finally, to further determine whether allelic variation found in 
these loci is likely to have functional influence on bacterial leaf blight resistance, we use SNPEFF [74] to predict whether significantly associated SNPs have a robust predicted effect on functional outcomes. Our findings indicated that the most likely source of novel BLB resistance genes is chromosome 11 due to its yielding of the greatest number of significantly associated SNPs most of which are on unlinked regions of the chromosome from $R$ genes. For this chromosome, we conducted further analyses on identified stress response gene sequence data to identify haplotypes based on presence/absence of significantly associated alleles. We describe this haplotypic variation and conducted ANOVA analysis on its correlation with phenotypic variation in BLB resistance across accessions.

\section{Conclusions}

Our study provides new insight into the genomic basis of bacterial blight resistance in rice. We anticipate that our findings will be useful for the development of BLB resistant rice lines in research programs in both Thailand and also other locations. Our focal rice accessions that we have mapped and indicated novel loci will hopefully provide more available material in breeding programs aimed at developing BLB resistance in different rice growing regions. Future research should focus on validating the effects of our identified candidate markers and characterizing their functional effects with respect to BLB resistance.

Supplementary Materials: The following are available online at https:/ /www.mdpi.com/2223-774 7/10/3/518/s1. Figure S1. See "Supplementary File 1.docx". Figure S2. See "Supplementary File 1.docx". Table S1. See "Supplementary File 1.docx". Table S2a; see "Supplementary File 1.docx" for title, and "Supplementary File 2.pdf" for Python program generated output. Table S2b; see "Supplementary File 1.docx" for title and "Supplementary File 3.pdf" for Python program generated output. Table S3. See "Supplementary File 1.docx". Table S4. See "Supplementary File 1.docx". Figure 2. See "Supplementary data file 1.csv" for phenotypic data.

Author Contributions: T.T., S.P., S.W., B.T., S.K. (Siripar Korinsak) and S.K. (Siriporn Korinsak) conceived and designed the experiment. S.K. (Siriporn Korinsak), S.P., L.P. conducted the experiments. C.T.D., S.K. (Siriporn Korinsak), S.W., S.P., analyzed the data. C.T.D., S.K. (Siriporn Korinsak), T.T. wrote the manuscript. S.W., C.T.D., S.K. (Siriporn Korinsak), revised the final version of the paper. S.K. (Siriporn Korinsak), and C.T.D. contributed equally to this work. All authors have read and agreed to the published version of the manuscript.

Funding: This study was supported by grants from National Science and Technology Development Agency, Thailand (NSTDA grant numbers: P-16-50297 and P-18-51456).

Institutional Review Board Statement: Not applicable.

Informed Consent Statement: Not applicable.

Data Availability Statement: The data supporting the conclusions of this article are included within the article and its additional files. PYTHON programming files available at: https://github.com/ ctdarwell/TASSELmanip.

Acknowledgments: Not applicable.

Conflicts of Interest: The authors declare no conflict of interest.

\section{References}

1. Huerta, A.I.; Delorean, E.E.; Bossa-Castro, A.M.; Tonnessen, B.W.; Raghavan, C.; Corral, R.; Pérez-Quintero, Á.L.; Leung, H.; Verdier, V.; Leach, J.E. Resistance and susceptibility QTL identified in a rice MAGIC population by screening with a minor-effect virulence factor from Xanthomonas oryzae pv. oryzae. Plant Biotechnol. J. 2021, 19, 51-63. [CrossRef] [PubMed]

2. Mew, T.W.; Cruz, C.V.; Medalla, E.S. Changes in race frequency of Xanthomonas oryzae pv. oryzae in response to rice cultivars planted in the Philippines. Plant Dis. 1992, 76, 1029-1032. [CrossRef]

3. Ou, S.H. Rice Diseases; Commonwealth Mycological Institute: Kew, UK, 1985.

4. Saha, S.; Garg, R.; Biswas, A.; Rai, A.B. Bacterial diseases of rice: An overview. J. Pure Appl. Microbiol. 2015, 9, 725-736.

5. Srinivasan, B.; Gnanamanickam, S.S. Identification of a new source of resistance in wild rice, Oryza rufipogon to bacterial blight of rice caused by Indian strains of Xanthomonas oryzae pv. oryzae. Curr. Sci. 2005, 88, 1229-1231.

6. Gautam, H.R.; Bhardwaj, M.L.; Kumar, R. Climate change and its impact on plant diseases. Curr. Sci. 2013, 105, $1685-1691$. 
7. Reddy, A.P.K.; Mackenzie, D.R.; Rouse, D.I.; Rao, A.V. Relationship of bacterial leaf blight severity to grain yield of rice. Phytopathology 1979, 69, 967-969. [CrossRef]

8. Schaad, N.W. Emerging plant pathogenic bacteria and global warming. In Pseudomonas syringae Pathovars and Related PathogensIdentification, Epidemiology and Genomics; Fatmi, M., Collmer, A., Iacobellis, N.S., Mansfield, J.W., Murillo, J., Schaad, N.W., Ullrich, M., Eds.; Springer: Berlin/Heidelberg, Germany, 2008; pp. 369-379.

9. Chien, C.-C.; Chou, M.-Y.; Chen, C.-Y.; Shih, M.-C. Analysis of genetic diversity of Xanthomonas oryzae pv. oryzae populations in Taiwan. Sci. Rep. 2019, 9, 316. [CrossRef] [PubMed]

10. Luo, H.-Z.; Guan, Y.; Yang, R.; Qian, G.-L.; Yang, X.-H.; Wang, J.-S.; Jia, A.-Q. Growth inhibition and metabolomic analysis of Xanthomonas oryzae pv. oryzae treated with resveratrol. BMC Microbiol. 2020, 20, 117. [CrossRef] [PubMed]

11. Ochiai, H.; Inoue, Y.; Takeya, M.; Sasaki, A.; Kaku, H. Genome Sequence of Xanthomonas oryzae pv. oryzae Suggests Contribution of Large Numbers of Effector Genes and Insertion Sequences to Its Race Diversity. JARQ 2005, 39, 275-287. [CrossRef]

12. Kosawang, C.; Smitamana, P.; Toojinda, T.; Nilpanit, N.; Sirithunya, P. Amplified Fragment Length Polymorphism Fingerprinting Differentiates Genetic Diversity of Xanthomonas oryzae pv. oryzae from Northern Thailand. J. Phytopathol. 2006, 154, 550-555. [CrossRef]

13. Sriprakorn, S. Identification and Geographical Distribution of Bacterial Leaf Blight Isolates (Xanthomonas oryzae pv. oryzae) and Tagging Resistance Genes in a Landrace. Master's Thesis, Kasetsart University, Bangkok, Thailand, 2009.

14. Apinyapanich, S. Studies on host range of Xanthomonas campestris Pv. Oryzae [rice] and chemical control. Master's Thesis, Kasetsart University, Bangkok, Thailand, 1983.

15. Adhikari, T.B.; Cruz, C.; Zhang, Q.; Nelson, R.J.; Skinner, D.Z.; Mew, T.W.; Leach, J.E. Genetic Diversity of Xanthomonas oryzae pv. oryzae in Asia. Appl. Environ. Microbiol. 1995, 61, 966-971. [CrossRef] [PubMed]

16. Gautam, R.K.; Singh, P.K.; Sakthivel, K.; Srikumar, M.; Kumar, N.; Kumar, K.; Singh, A.K.; Roy, S.D. Analysis of Pathogenic Diversity of the Rice Bacterial Blight Pathogen (Xanthomonas oryzae pv. oryzae) in the Andaman Islands and Identification of Effective Resistance Genes. J. Phytopathol. 2015, 163, 423-432. [CrossRef]

17. Gnanamanickam, S.S.; Priyadarisini, V.B.; Narayanan, N.N. An overview of bacterial blight disease of rice and strategies for its management. Curr. Sci. 1999, 77, 1435-1444.

18. McDowell, J.M.; Woffenden, B.J. Plant disease resistance genes: Recent insights and potential applications. Trends Biotechnol. 2003, 21, 178-183. [CrossRef]

19. Chen, X.L.; Yu, L.; Gao, L.L.; Jiang, T.; Li, Q.Y.; Huang, Q. Elevational Variation in Diversity of Xanthomonas oryzae pv. oryzae in South-West China. J. Phytopathol. 2012, 160, 261-268. [CrossRef]

20. Nelson, R.; Wiesner-Hanks, T.; Wisser, R.; Balint-Kurti, P. Navigating complexity to breed disease-resistant crops. Nat. Rev. Genet. 2018, 19, 21-33. [CrossRef]

21. Bhatia, D.; Lore, J.S.; Vikal, Y.; Gupta, V. Screening of Oryza species germplasm against a new variant of Xanthomonas oryzae pv. oryzae causing bacterial blight in Punjab. Plant Dis. 2010, 25, 44-47.

22. Kumar, S.; Dwivedi, S.K.; Kumar, R.; Bhakta, N. Screening of different rice germplasm against multiple disease under submergence condition in middle Indo Gangetic Plain. Int. J. Curr. Microbiol. Appl. Sci. 2017, 6, 335-339. [CrossRef]

23. Abbasi, F.M.; Masood, R.; Ahmad, H.; Khan, U. Molecular screening of Pakistani rice germplasm for xa5 gene resistance to bacterial blight. Afr. J. Biotechnol. 2011, 10, 2833-2837.

24. Dilla-Ermita, C.J.; Tandayu, E.; Juanillas, V.M.; Detras, J.; Lozada, D.N.; Dwiyanti, M.S.; Vera Cruz, C.; Mbanjo, E.G.N.; Ardales, E.; Diaz, M.G.; et al. Genome-wide Association Analysis Tracks Bacterial Leaf Blight Resistance Loci In Rice Diverse Germplasm. Rice 2017, 10, 8. [CrossRef] [PubMed]

25. Kim, S.-M.; Reinke, R.F. A novel resistance gene for bacterial blight in rice, Xa43(t) identified by GWAS, confirmed by QTL mapping using a bi-parental population. PLoS ONE 2019, 14, e0211775. [CrossRef] [PubMed]

26. Guo, S.B.; Zhang, D.P.; Lin, X.H. Identification and mapping of a novel bacterial blight resistance gene Xa35 ( $\mathrm{t}$ ) originated from Oryza minuta. Sci. Agric. Sin. 2010, 43, 2611-2618.

27. Bhasin, H.; Bhatia, D.; Raghuvanshi, S.; Lore, J.S.; Sahi, G.K.; Kaur, B.; Vikal, Y.; Singh, K. New PCR-based sequence-tagged site marker for bacterial blight resistance gene Xa38 of rice. Mol. Breed. 2012, 30, 607-611. [CrossRef]

28. Ellur, R.K.; Khanna, A.; Bhowmick, P.K.; Vinod, K.K.; Nagarajan, M.; Mondal, K.K.; Singh, N.K.; Singh, K.; Prabhu, K.V.; Singh, A.K.; et al. Marker-aided Incorporation of Xa38, a Novel Bacterial Blight Resistance Gene, in PB1121 and Comparison of its Resistance Spectrum with xa13 + Xa21. Sci. Rep. 2016, 6, 29188. [CrossRef]

29. Kim, S.-M.; Suh, J.-P.; Qin, Y.; Noh, T.-H.; Reinke, R.F.; Jena, K.K. Identification and fine-mapping of a new resistance gene, Xa40, conferring resistance to bacterial blight races in rice (Oryza sativa L.). Appl. Genet. 2015, 128, 1933-1943. [CrossRef]

30. Zhang, F.; Zhuo, D.L.; Zhang, F.; Huang, L.Y.; Wang, W.S.; Xu, J.L.; Vera Cruz, C.; Li, Z.K.; Zhou, Y.L. Xa39, a novel dominant gene conferring broad-spectrum resistance to Xanthomonas oryzae pv. oryzae in rice. Plant Pathol. 2015, 64, 568-575. [CrossRef]

31. Liang, L.Q.; Wang, C.Y.; Zeng, L.X.; Wang, W.J.; Feng, J.Q.; Chen, B.; Su, J.; Chen, S.; Shang, F.D.; Zhu, X.Y.; et al. The rice cultivar Baixiangzhan harbours a recessive gene xa42 ( $t$ ) determining resistance against Xanthomonas oryzae pv. oryzae. Plant Breed. 2017, 136, 603-609. [CrossRef]

32. Miao, L.L.; Wang, C.L.; Zheng, C.K.; Che, J.Y.; Gao, Y. Molecular mapping of a new gene for resistance to rice bacterial blight. Sci. Agric. 2010, 43, 3051-3058. 
33. Busungu, C.; Taura, S.; Sakagami, J.-I.; Ichitani, K. Identification and linkage analysis of a new rice bacterial blight resistance gene from XM14, a mutant line from IR24. Breed. Sci. 2016, 66, 636-645. [CrossRef] [PubMed]

34. Chen, S.; Wang, C.; Yang, J.; Chen, B.; Wang, W.; Su, J.; Feng, A.; Zeng, L.; Zhu, X. Identification of the novel bacterial blight resistance gene Xa46(t) by mapping and expression analysis of the rice mutant H120. Sci. Rep. 2020, 10, 12642. [CrossRef] [PubMed]

35. Chukwu, S.C.; Rafii, M.Y.; Ramlee, S.I.; Ismail, S.I.; Hasan, M.M.; Oladosu, Y.A.; Magaji, U.G.; Akos, I.; Olalekan, K.K. Bacterial leaf blight resistance in rice: A review of conventional breeding to molecular approach. Mol. Biol. Rep. 2019, 46, 1519-1532. [CrossRef]

36. Win, K.M.; Korinsak, S.; Sirithunya, P.; Lanceras-Siangliw, J.; Jamboonsri, W.; Da, T.; Patarapuwadol, S.; Toojinda, T. Marker assisted introgression of multiple genes for bacterial blight resistance into aromatic Myanmar rice MK-75. Field Crop. Res. 2013, 154, 164-171. [CrossRef]

37. Vikal, Y.; Bhatia, D. Geneticsand genomics of bacterial blight resistance in rice. In Advances in International Rice Research; Jin, Q.L., Ed.; Intech: Rijeka, Croatia, 2017.

38. Liu, Q.; Yuan, M.; Zhou, Y.; Li, X.; Xiao, J.; Wang, S. A paralog of the MtN3/saliva family recessively confers race-specific resistance to Xanthomonas oryzae in rice. Plant Cell Environ. 2011, 34, 1958-1969. [CrossRef]

39. Song, W.Y.; Wang, G.L.; Chen, L.L.; Kim, H.S.; Pi, L.Y.; Holsten, T.; Gardner, J.; Wang, B.; Zhai, W.X.; Zhu, L.H.; et al. A receptor kinase-like protein encoded by the rice disease resistance gene, Xa21. Science 1995, 270, 1804-1806. [CrossRef] [PubMed]

40. Iyer, A.S.; McCouch, S.R. The rice bacterial blight resistance gene xa5 encodes a novel form of disease resistance. Mol. Plant Microbe Interact. 2004, 17, 1348-1354. [CrossRef] [PubMed]

41. Tian, D.; Wang, J.; Zeng, X.; Gu, K.; Qiu, C.; Yang, X.; Zhou, Z.; Goh, M.; Luo, Y.; Murata-Hori, M.; et al. The rice TAL effectordependent resistance protein XA10 triggers cell death and calcium depletion in the endoplasmic reticulum. Plant Cell 2014, 26, 497-515. [CrossRef] [PubMed]

42. Sun, X.; Cao, Y.; Yang, Z.; Xu, C.; Li, X.; Wang, S.; Zhang, Q. Xa26, a gene conferring resistance to Xanthomonas oryzae pv. oryzae in rice, encodes an LRR receptor kinase-like protein. Plant J. 2004, 37, 517-527. [CrossRef]

43. Chu, Z.; Fu, B.; Yang, H.; Xu, C.; Li, Z.; Sanchez, A.; Park, Y.J.; Bennetzen, J.L.; Zhang, Q.; Wang, S. Targeting xa13, a recessive gene for bacterial blight resistance in rice. Appl. Genet. 2006, 112, 455-461. [CrossRef]

44. Wang, C.; Zhang, X.; Fan, Y.; Gao, Y.; Zhu, Q.; Zheng, C.; Qin, T.; Li, Y.; Che, J.; Zhang, M.; et al. XA23 is an executor R protein and confers broad-spectrum disease resistance in rice. Mol. Plant 2014, 8, 290-302. [CrossRef]

45. Yoshimura, S.; Yamanouchi, U.; Katayose, Y.; Toki, S.; Wang, Z.X.; Kono, I.; Kurata, N.; Yano, M.; Iwata, N.; Sasaki, T. Expression of Xa1, a bacterial blight-resistance gene in rice, is induced by bacterial inoculation. Proc. Natl. Acad. Sci. USA 1998, 95, 1663-1668. [CrossRef]

46. $\mathrm{Wu}, \mathrm{X} . ; \mathrm{Li}, \mathrm{X}$; $\mathrm{Xu}, \mathrm{C}$; Wang, S. Fine genetic mapping of xa24, a recessive gene for resistance against Xanthomonas oryzae pv. oryzae in rice. Theor. Appl. Genet. 2008, 118, 185-191. [CrossRef] [PubMed]

47. Wu, L.; Goh, M.L.; Sreekala, C.; Yin, Z. XA27 depends on an amino-terminal signal-anchor-like sequence to localize to the apoplast for resistance to Xanthomonas oryzae pv oryzae. Plant Physiol. 2008, 148, 1497-1509. [CrossRef]

48. Xiang, Y.; Cao, Y.; Xu, C.; Li, X.; Wang, S. Xa3, conferring resistance for rice bacterial blight and encoding a receptor kinase-like protein, is the same as Xa26. Theor. Appl. Genet. 2006, 113, 1347-1355. [CrossRef] [PubMed]

49. Kraakman, A.T.W.; Niks, R.E.; Van den Berg, P.M.M.M.; Stam, P.; Van Eeuwijk, F.A. Linkage disequilibrium mapping of yield and yield stability in modern spring barley cultivars. Genetics 2004, 168, 435-446. [CrossRef] [PubMed]

50. Brachi, B.; Morris, G.P.; Borevitz, J.O. Genome-wide association studies in plants: The missing heritability is in the field. Genome Biol. 2011, 12, 232. [CrossRef]

51. Racedo, J.; Gutiérrez, L.; Perera, M.F.; Ostengo, S.; Pardo, E.M.; Cuenya, M.I.; Welin, B.; Castagnaro, A.P. Genome-wide association mapping of quantitative traits in a breeding population of sugarcane. BMC Plant Biol. 2016, 16, 142. [CrossRef]

52. Nakano, Y.; Kobayashi, Y. Genome-wide Association Studies of Agronomic Traits Consisting of Field- and Molecular-based Phenotypes. Rev. Agric. Sci. 2020, 8, 28-45. [CrossRef]

53. Verdeprado, H.; Kretzschmar, T.; Begum, H.; Raghavan, C.; Joyce, P.; Lakshmanan, P.; Cobb, J.N.; Collard, B.C.Y. Association mapping in rice: Basic concepts and perspectives for molecular breeding. Plant Prod. Sci. 2018, 21, 159-176. [CrossRef]

54. Zhang, F.; Wu, Z.-C.; Wang, M.-M.; Zhang, F.; Dingkuhn, M.; Xu, J.-L.; Zhou, Y.-L.; Li, Z.-K. Genome-wide association analysis identifies resistance loci for bacterial blight in a diverse collection of indica rice germplasm. PLOS ONE 2017, 12, e0174598. [CrossRef]

55. Bossa-Castro, A.M.; Tekete, C.; Raghavan, C.; Delorean, E.E.; Dereeper, A.; Dagno, K.; Koita, O.; Mosquera, G.; Leung, H.; Verdier, V.; et al. Allelic variation for broad-spectrum resistance and susceptibility to bacterial pathogens identified in a rice MAGIC population. Plant Biotechnol. J. 2018, 16, 1559-1568. [CrossRef]

56. Kawasaki-Tanaka, A.; Fukuta, Y. Genetic variation in resistance to blast disease (Pyricularia oryzae Cavara) in Japanese rice (Oryza sativa L.), as determined using a differential system. Breed. Sci. 2014, 64, 183-192. [CrossRef]

57. Descalsota, G.I.L.; Swamy, B.P.M.; Zaw, H.; Inabangan-Asilo, M.A.; Amparado, A.; Mauleon, R.; Chadha-Mohanty, P.; Arocena, E.C.; Raghavan, C.; Leung, H.; et al. Genome-Wide Association Mapping in a Rice MAGIC Plus Population Detects QTLs and Genes Useful for Biofortification. Front. Plant Sci. 2018, 9, 1347. [CrossRef]

58. Chen, Z.; Feng, Z.; Kang, H.; Zhao, J.; Chen, T.; Li, Q.; Gong, H.; Zhang, Y.; Chen, X.; Pan, X.; et al. Identification of New Resistance Loci Against Sheath Blight Disease in Rice Through Genome-Wide Association Study. Rice Sci. 2019, 26, 21-31. [CrossRef] 
59. Huang, X.; Wei, X.; Sang, T.; Zhao, Q.; Feng, Q.; Zhao, Y.; Li, C.; Zhu, C.; Lu, T.; Zhang, Z.; et al. Genome-wide association studies of 14 agronomic traits in rice landraces. Nat. Genet. 2010, 42, 961-967. [CrossRef] [PubMed]

60. Hur, Y.-J.; Cho, J.-H.; Park, H.-S.; Noh, T.-H.; Park, D.-S.; Lee, J.Y.; Sohn, Y.-B.; Shin, D.; Song, Y.C.; Kwon, Y.-U.; et al. Pyramiding of two rice bacterial blight resistance genes, $\mathrm{Xa3}$ and $\mathrm{Xa} 4$, and a closely linked cold-tolerance QTL on chromosome 11. Appl. Genet. 2016, 129, 1861-1871. [CrossRef]

61. Petpisit, V.; Khush, G.S.; Kauffman, H.E. Inheritance of resistance to bacterial blight in rice ${ }^{1}$. Crop Sci. 1977, 17, 551-554. [CrossRef]

62. Streubel, J.; Pesce, C.; Hutin, M.; Koebnik, R.; Boch, J.; Szurek, B. Five phylogenetically close rice SWEET genes confer TAL effector-mediated susceptibility to Xanthomonas oryzae pv. oryzae. New Phytol. 2013, 200, 808-819. [CrossRef]

63. NIÑO-LIU, D.O.; Ronald, P.C.; Bogdanove, A.J. Xanthomonas oryzae pathovars: Model pathogens of a model crop. Mol. Plant Pathol. 2006, 7, 303-324. [CrossRef] [PubMed]

64. Li, Z.K.; Arif, M.; Zhong, D.B.; Fu, B.Y.; Xu, J.L.; Domingo-Rey, J.; Ali, J.; Vijayakumar, C.H.M.; Yu, S.B.; Khush, G.S. Complex genetic networks underlying the defensive system of rice (Oryza sativa L.) to Xanthomonas oryzae pv. oryzae. Proc. Natl. Acad. Sci. USA 2006, 103, 7994-7999. [CrossRef] [PubMed]

65. Kauffman, H.E. An improved technique for evaluat-ing resistance of rice varieties to Xanthomonas oryzae. Plant Dis. Rep. 1973, 57, 537-541.

66. Danecek, P.; Auton, A.; Abecasis, G.; Albers, C.A.; Banks, E.; DePristo, M.A.; Handsaker, R.E.; Lunter, G.; Marth, G.T.; Sherry, S.T.; et al. 1000 Genomes Project Analysis Group The variant call format and VCFtools. Bioinformatics 2011, 27, 2156-2158. [CrossRef]

67. Shin, J.H.; Blay, S.; McNeney, B. LDheatmap: An R function for graphical display of pairwise linkage disequilibria between single nucleotide polymorphisms. J. Stat. Softw. 2006, 16, 1-19. [CrossRef]

68. Bradbury, P.J.; Zhang, Z.; Kroon, D.E.; Casstevens, T.M.; Ramdoss, Y.; Buckler, E.S. TASSEL: Software for association mapping of complex traits in diverse samples. Bioinformatics 2007, 23, 2633-2635. [CrossRef] [PubMed]

69. Yu, J.; Pressoir, G.; Briggs, W.H.; Vroh Bi, I.; Yamasaki, M.; Doebley, J.F.; McMullen, M.D.; Gaut, B.S.; Nielsen, D.M.; Holland, J.B.; et al. A unified mixed-model method for association mapping that accounts for multiple levels of relatedness. Nat. Genet. 2006, 38, 203-208. [CrossRef] [PubMed]

70. Blom, G. Statistical Estimates and Transformed beta-Variables. Ph.D. Thesis, Stockholm College, Stockholm, Sweden, 1958.

71. Benjamini, Y.; Hochberg, Y. Controlling the false discovery rate: A practical and powerful approach to multiple testing. J. R. Stat. Soc. Ser. B 1995, 57, 289-300. [CrossRef]

72. Rom, D.M. A sequentially rejective test procedure based on a modified Bonferroni inequality. Biometrika 1990, 77, 663-665. [CrossRef]

73. Ohyanagi, H.; Tanaka, T.; Sakai, H.; Shigemoto, Y.; Yamaguchi, K.; Habara, T.; Fujii, Y.; Antonio, B.A.; Nagamura, Y.; Imanishi, T.; et al. The Rice Annotation Project Database (RAP-DB): Hub for Oryza sativa ssp. japonica genome information. Nucleic Acids Res. 2006, 34, D741-D744. [CrossRef] [PubMed]

74. Cingolani, P.; Platts, A.; Wang, L.L.; Coon, M.; Nguyen, T.; Wang, L.; Land, S.J.; Lu, X.; Ruden, D.M. A program for annotating and predicting the effects of single nucleotide polymorphisms, SnpEff: SNPs in the genome of Drosophila melanogaster strain w1118; iso-2; iso-3. Fly 2012, 6, 80-92. [CrossRef] [PubMed] 